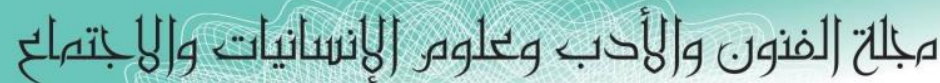
Journal of Arts, Literature, Humanities and Social Sciences

ISSN online: 2414 - 3383

ISSN print: 2616 - 3810

العدد (41) آب - أغلسطلس 2019

\title{
القيم التشكيلية الخطية لنباتات الصبار كمدخل لإثراء تصاميم المُعلقات المطبوعة المات الصبات
}

\author{
الاكتورة \\ جوزاء بنت فلاح بن مدلول العنزي

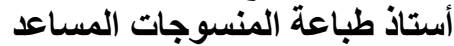 \\ قسم الفنون الجميلة ــ كلية الآداب والفنون المبات - جامعة حائل \\ المملكة العربية السعودية الآلية \\ dr.jowzafm15@gmail.com
}

|لماخص

يُعد الخط عنصر ا هاماً من عناصر التصميم؛ بل ويعتبر أداة كاملة بحد ذاته بيد المُصمم المُبدع؛ والخط من اقدم وسائل التعبير الفني التي تطورت مع تطور العصور وتغيرت مفاهيمه وتتوعت وظائفه وتعددت اشكاله؛ حتى اصبح اليوم ذا قيمة جمالية وتثكيلية وتعبيرية وبنائية عالية في اي عمل فني 1؛ فالخط لديه قابلية التأليف و التكوين التي تعطي الكثير من المعاني والاسس الخاصة بالتصميم؛ مثل الاتزان والثبات والحركه والديناميكبه؛ لذلك يسعى البحث الحالي الى الاستفادة من القيم التنكيلية الخطيه لنباتات الصبار كمخل لإثراء تصاميم المُعلقات المطبو عة يدوياً؛ حيث ان نباتات الصبار جُزء لا يتجز أ من الطبيعة في صحر اء الجزيرة العربية، وتعتبر ر افداً من رو افد الفن الحديث لو نم إستغلالها فنياً بشكل جيد؛ لما لها من خصائص تثكيلية فريدة في أنو اعها و أنشكالها

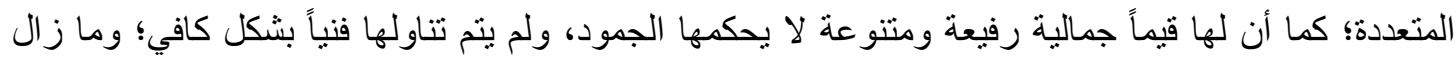
هناك مجال لدراسات فنية كثيرة عليها؛ ومن هنا انبثقت مشكلة البحث في معرفة قابلية نباتات الصبار لتطبيق در اسة فنية عليها مبنية على النظم التشكيلية الخطية لها؛ وهل بمكن أن نخرج منها بنظم تشكيلية خطيه جديدة تضيف للفن عموماً ولتصاميم طباعة المنسوجات خصوصاً.

1 ا ماني ناجي عبدالعزيز(2012): تأثير الخطوط على المسار البصري كمصدر لبغات معدنية مستحدثة، (دم:د.ن)،ص2. 
مبلحت (لفنون والأدب وعلوه الإنسانيات والبانتهاع

Journal of Arts, Literature, Humanities and Social Sciences

ISSN online: 2414 - 3383

ISSN print: 2616 - 3810

العدد (41) آب - أغسطس 2019

\title{
Linear Fine Line Values of Cactus Plants as an Input to Enrich Printed Leaf Designs
}

\begin{abstract}
The line is an important component of the design and it is a complete tool by itself in the hands of the creative designer or artist.The line is one of the oldest means of artistic expression, which has been developed with the evolution through the ages, the line has changed its concepts and now have varied functions and multiple forms and until today the line gained its artistic aesthetic value. Also, the line have the ability to be formed in any artwork which gives a lot of meanings and foundations for the design, however, the line has some elements such as balance, stability, movement, frequency, and dynamism. Therefore, the current research seeks to take advantage of the linear visual values of cactus plants as an entrance to enrich the designs of printable handmade pendants. Because the cactus plants are an integral part of nature in the desert of the Arabian Peninsula, they would be considered to be a tributary of modern art if they have been well exploited, technically because of their unique characteristics with its various types and forms. They also have high aesthetic values that are not limited to its inflexibility, and it does have various fields for researchers.From here, the research problem emerged to know more about the capability of the cactus plants to be under experiment to apply a technical study based on their linear morphological systems. and to know if we can get out with new linear systems that add to the art in general and especially for textile printing.
\end{abstract}




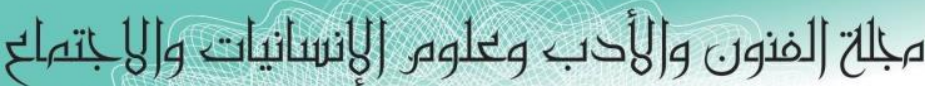

Journal of Arts, Literature, Humanities and Social Sciences

ISSN online: 2414 - 3383

ISSN print: 2616 - 3810

\section{العدد (41) آب - أغسطس 2019}

HALHSS

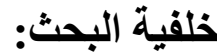

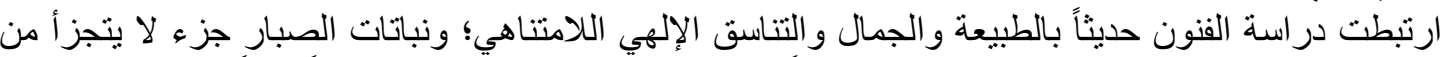
الطبيعة في صحر اء الجزيرة العربية، وتعتبر رافداً من رو افد الفن لو تم إستغلالها جمالياً وفنياً بشكل جيد؛ لما لها لها

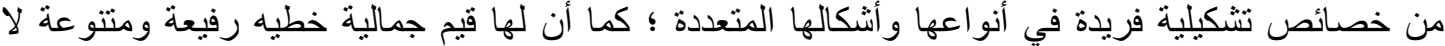

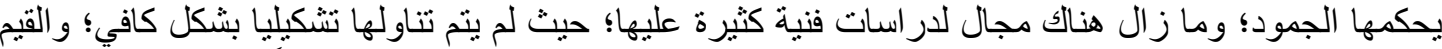

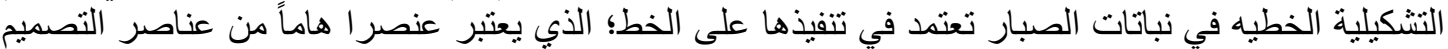

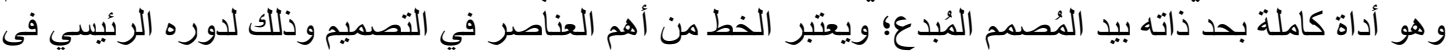

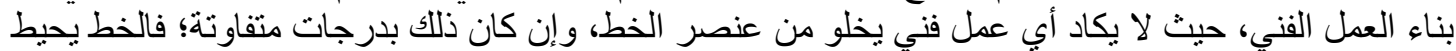

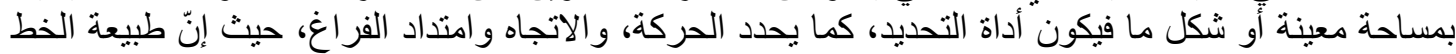

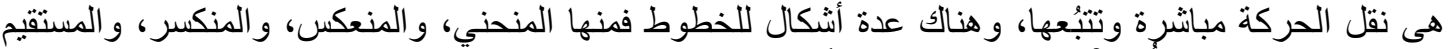

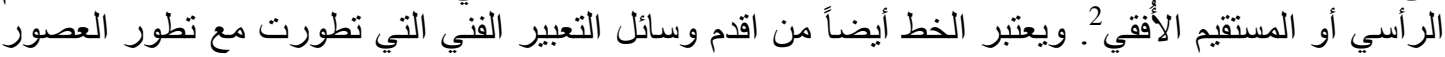
وتغيرت مفاهيمه وتتو عت وظائفه وتعددت اشكاله؛ حتى اصبح اليوم ذا قيمة فنية تشكيلية وتعبيرية وبنائية في اي

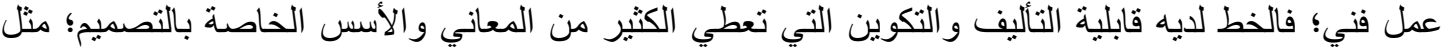

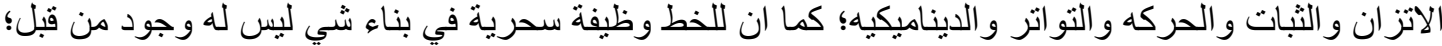

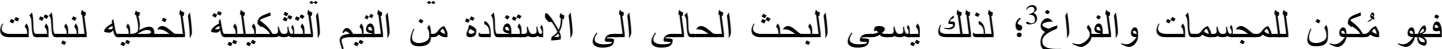

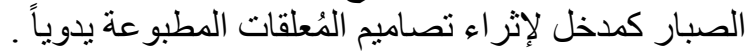

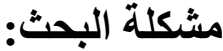

مما سبق يكن تحديد مشكلة البحث في التساؤلين الرئيسيين التاليين:

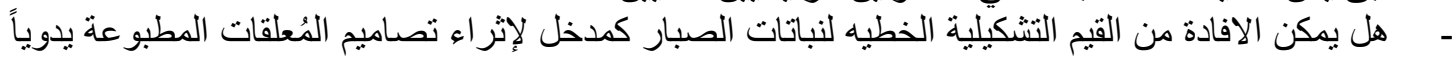

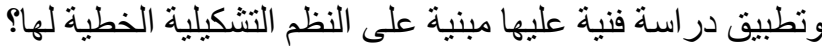

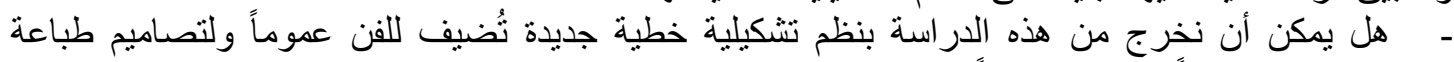

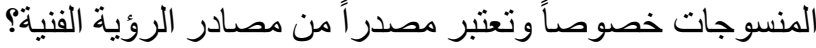

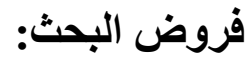
يفترض البحث أن: - در اسة القيم التشكيلية الخطيه لنباتات الصبار كمدخل لإثر اء تصاميم المُعلقات المطبو عة يدوياً قد بسهم في تطوير جو انب استحداث التصاميم الطباعية للمعلقات. - تطبيق دراسة فنية على أنواع من نباتات الصبار ومقوماتها التشكيلية الخطيه ومافيها من نظم إيقاعية وقيم

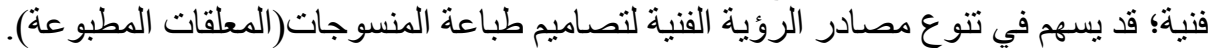

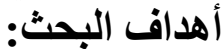
بهذف البحث: إلى: البه:

- ـ - لتعرف على القيم التشكيلية الخطية لنباتات الصبار كمصدر من مصادر الالهام و الرؤية الفنية المعاصرة.

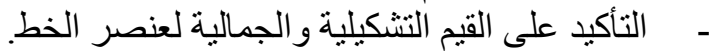
- - استخدام إمكانات إحدى بر امج تحرير الصور في الهواتف الذكية في محاولة تقديم نماذج لتصميمات طباعية

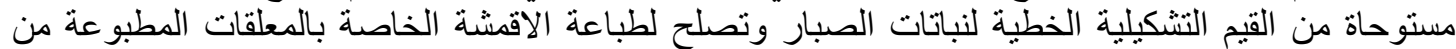

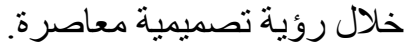

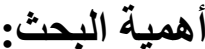
تتلخص أهمية البحث فيث الفئ ـ در اسة القيم التشكيلية الخطية لنباتات الصبار كمصدر من مصدادر الالهام و الرؤية الفنية المعاصرة.

https://mawdoo3.com/\%D8\%B9\%D9\%86\%D8\%A7\%D8\%B5\%D8\%B1 \%D8\%A7\%D9\%84\%D9\%81\%D9\%86 ${ }^{2}$ 3 مايز،برنارد(1966): الفنون التشكيلية كيف نتذوقها، ترجمة سعد المنصوري، مكتبة النهضه المصريه،القاهره ،ص238 


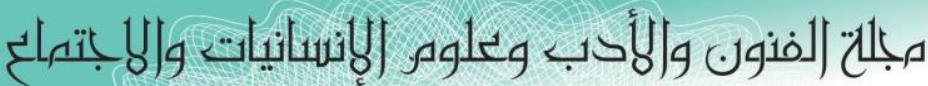

Journal of Arts, Literature, Humanities and Social Sciences

ISSN online: 2414 - 3383

ISSN print: 2616 - 3810

\section{العدد (41) آب - أغسطس 2019}

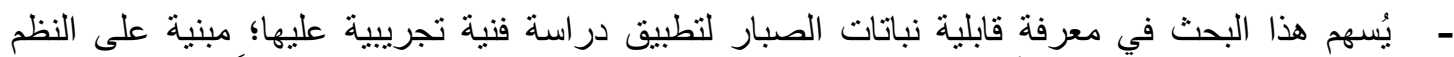

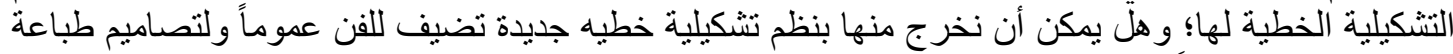

المنسوجات خصو صناً. - ـ يُسهم هذا البحث في بناء قيم تشكيلية خطيه جديدة ومبتكرة من خلال الاتجاهات الحديثة؛ لإثراء مجال تصاميم المُعلقات المطبو عة يدوياً بعيدة عن الرتابة و الملائل

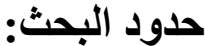
تتحدد الدر اسة في: الفود: - در اسة بعض النماذج الطبيعية لنباتات الصبار.

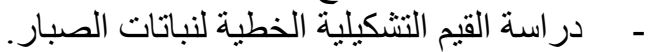

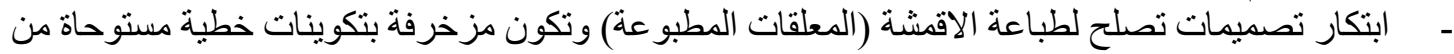
القيم التثكيلية الخطية لنباتات الصبار من خلال استخدام إمكانات إحدى برامج التحرن تحرير الصور في الهو اتف الذكية. منهج البحث:

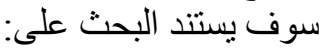

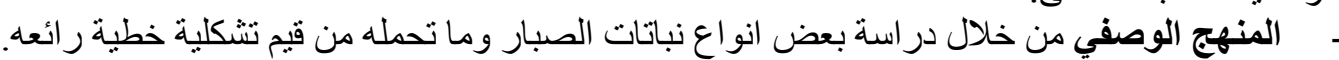

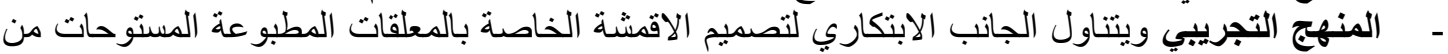
القيم التشكيلية الخطية لنباتات الصبار وذلك من خلال استخدام إمكانات إحدى برامج التحرئ تحرير الصور في الهو اتف

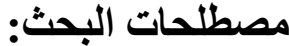 القيم التثكيلية الخطية وتعتمد على الخط كعنصر هام في التصميم.

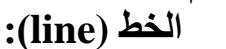

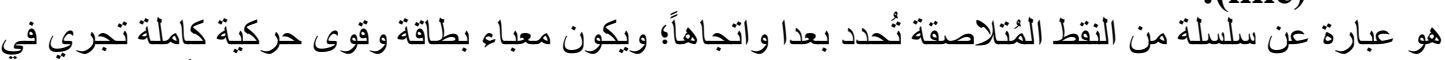

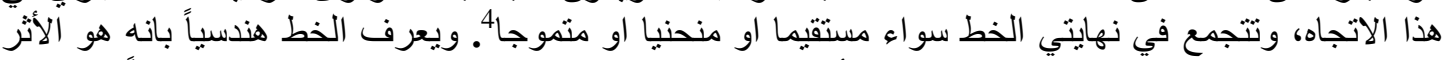

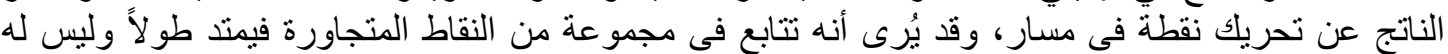

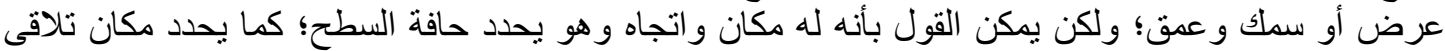

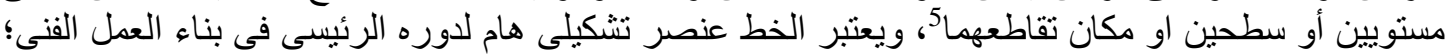

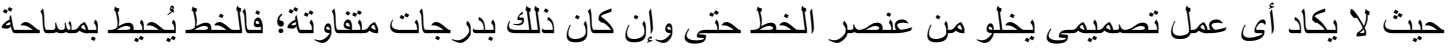

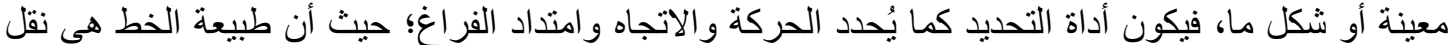

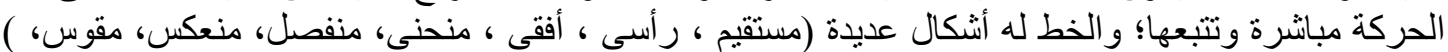

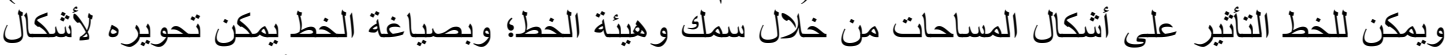

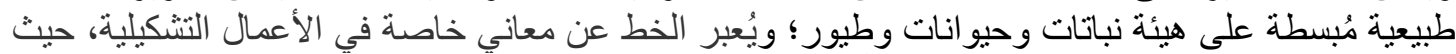

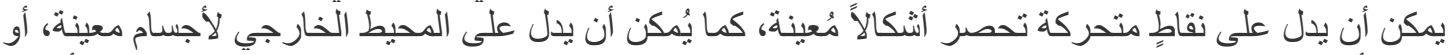

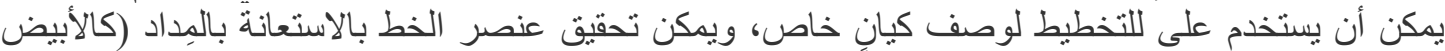
و الأسود) وقد يُعبر عن دلالات أخرى مثل: الثُعور بالحركة، أو الاندفاع، أو الاستقر ار و الثبات.

-

هو كل ماهو معلق ويتدلى من اعلى الى أسفل؛ و المقصود بها في هذه الدر اسة الاقمشة ذات القيم الفنبة العالية التي تُصمح

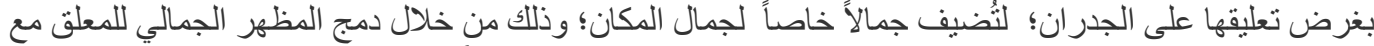

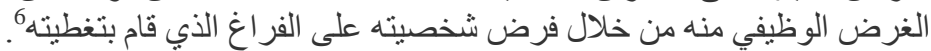

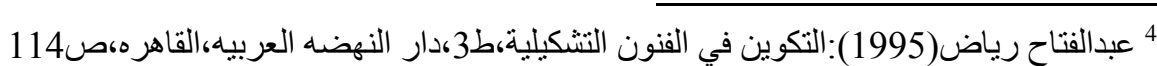

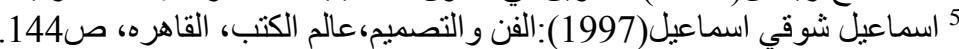

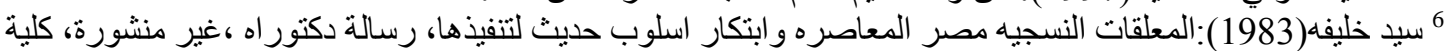

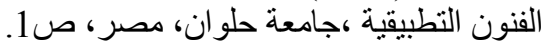




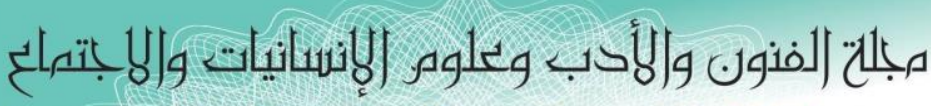
Journal of Arts, Literature, Humanities and Social Sciences

ISSN online: 2414 - 3383

ISSN print: 2616 - 3810

\section{العدد (41) آب - أغسطس 2019}

HALHSS

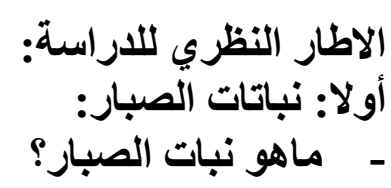

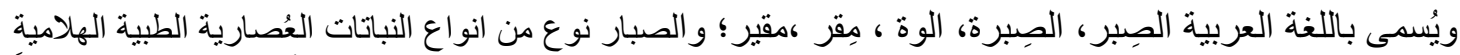

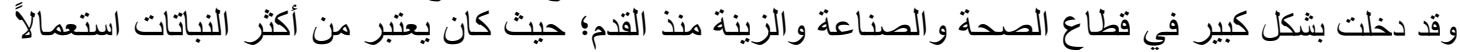

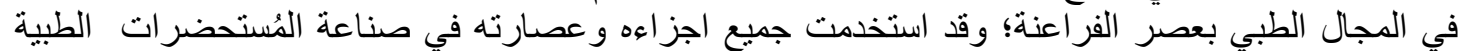

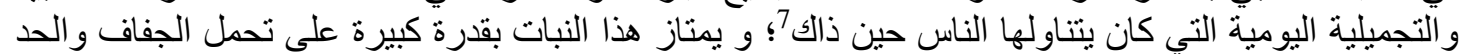

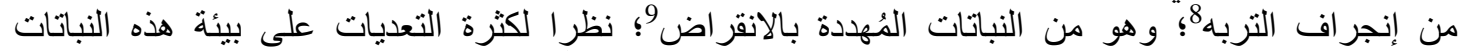

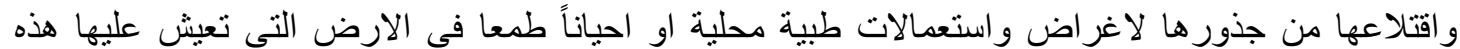

النباتات.

-

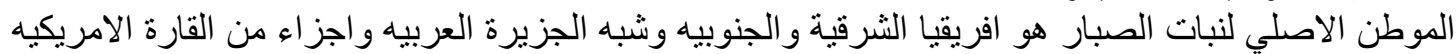

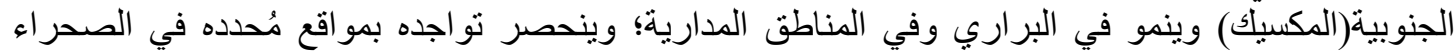

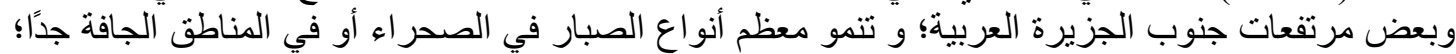

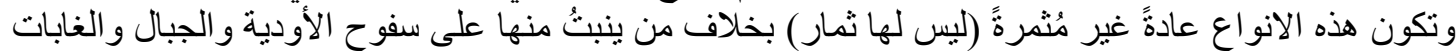

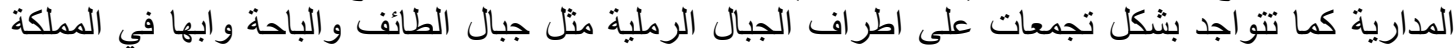

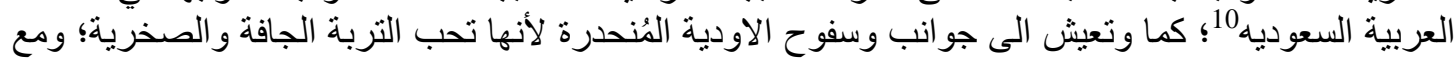

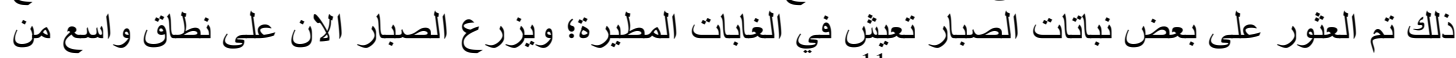

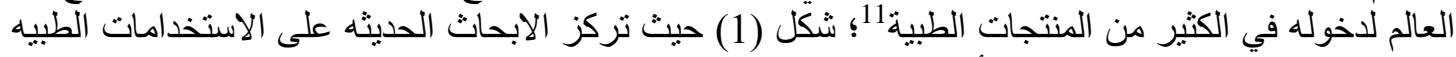

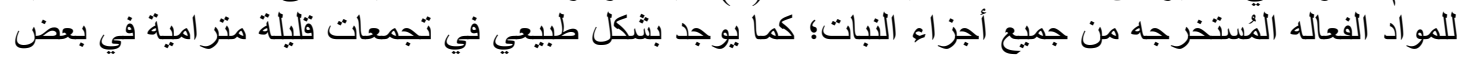

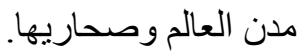

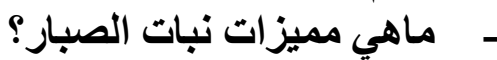

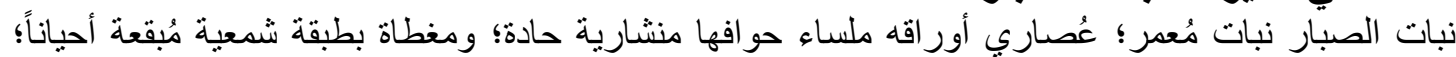

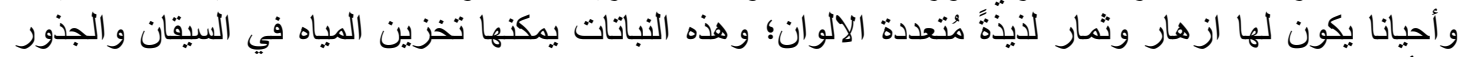

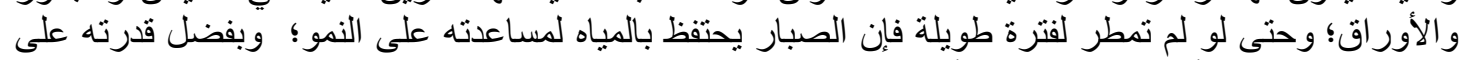

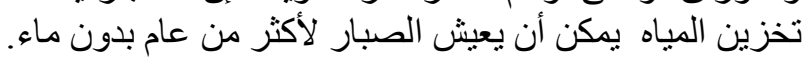

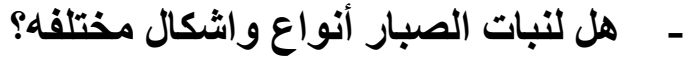

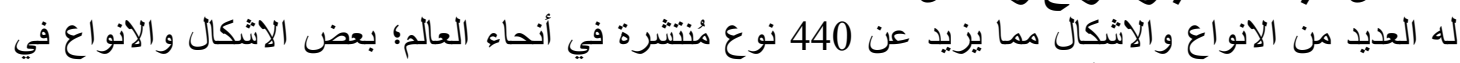

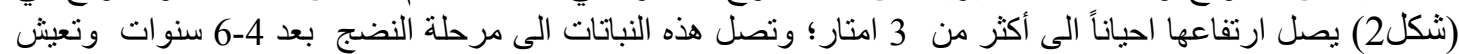

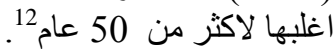

Agarry,O,O, Olaleye, M ,T (2005):Comparative Antimicrobial, Activities Of Aloe Vera gel 7 and leaf.J.Biotechnol.4,(12),1413-1414. Reynolds, T,Dweck,A,C(1999): Aloe vera Leaf gel, a review update,J,Ethnopharmacol,68,3- ${ }^{8}$ 9 و احمد العطيات(1993): موسوعة النباتات الطبية اثار ها العلاجيه او الفسيولو جيه، اجزاؤها النباتية وعقاقيرها الكيمائة، المؤسسة العربية للار اسات والنشر ، بيروت ، لبنات البنان. http://www.naseemnajd.com/w/?p=89 ${ }^{10}$

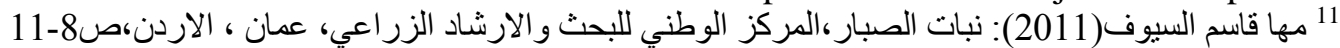
https://www.khayma.com.hawij ${ }^{12}$ 


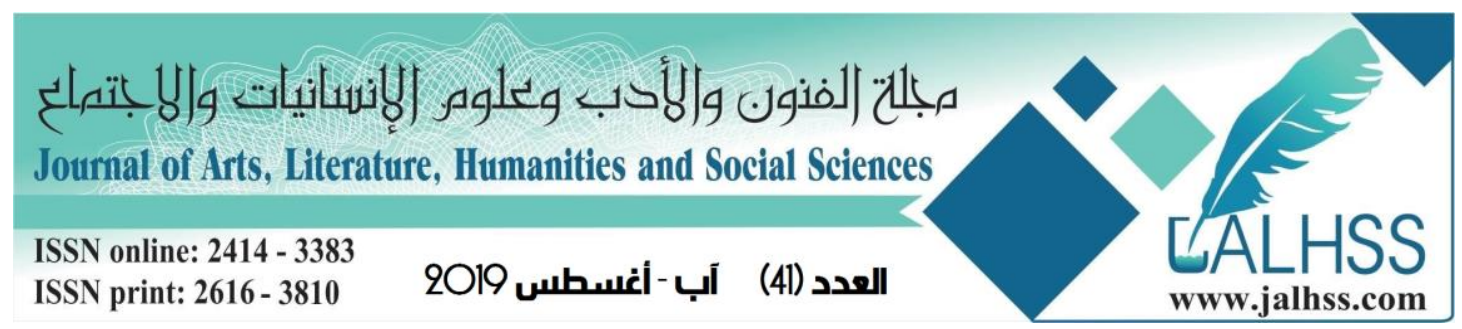

بعض اشكال وأنواع نباتات الصبار في الجزيرة العربية

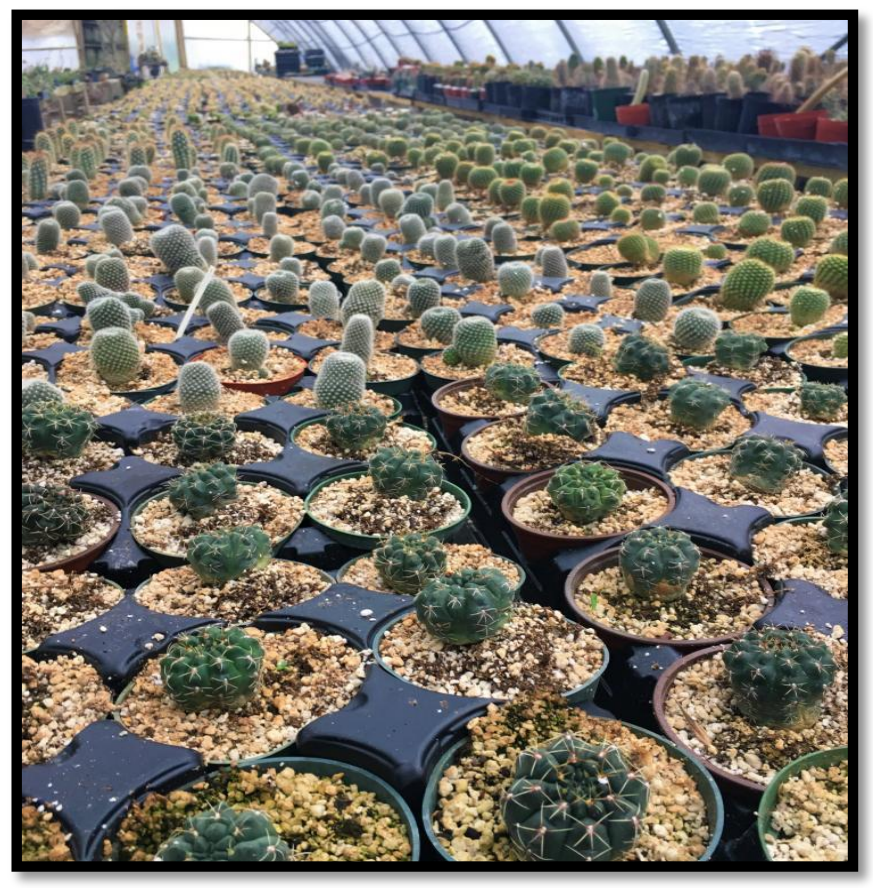

شكل (1) زراعة نباتات الصبار على نطاق واسع في الجزيرة العربية.

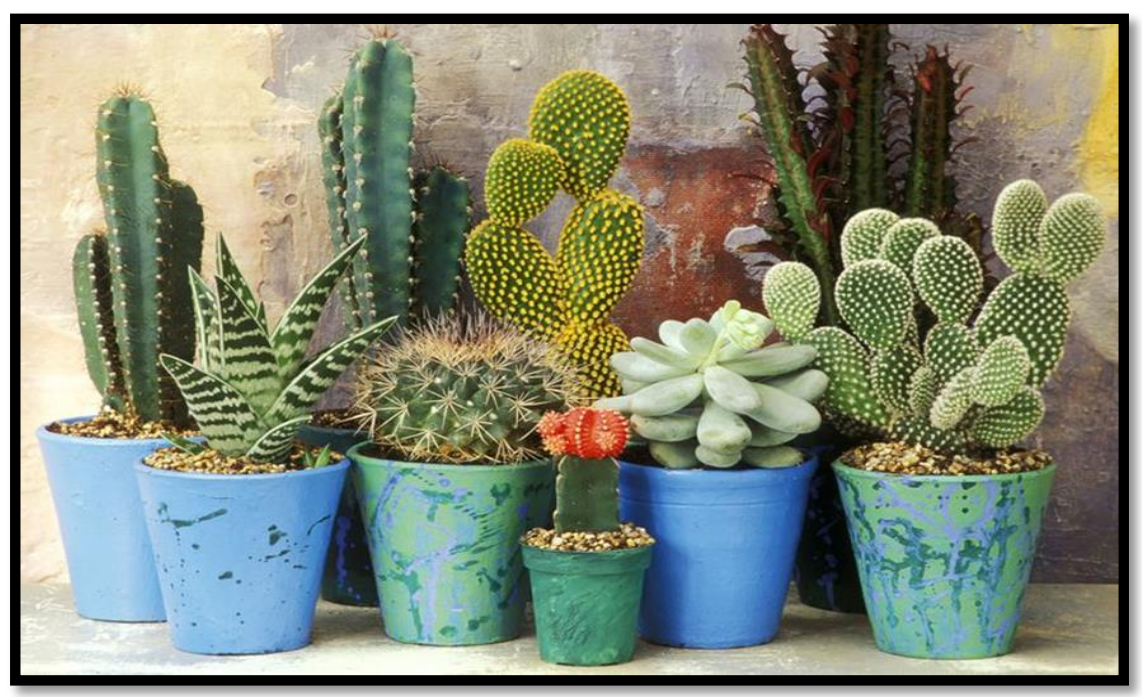

شكل (2) أثكال وانواع متعددة من نباتات الصبار

( مراجع صور الصبار

https://www.etsy.com/listing/628259134/opuntia-monacantha-drooping-prickly ${ }^{13}$ 

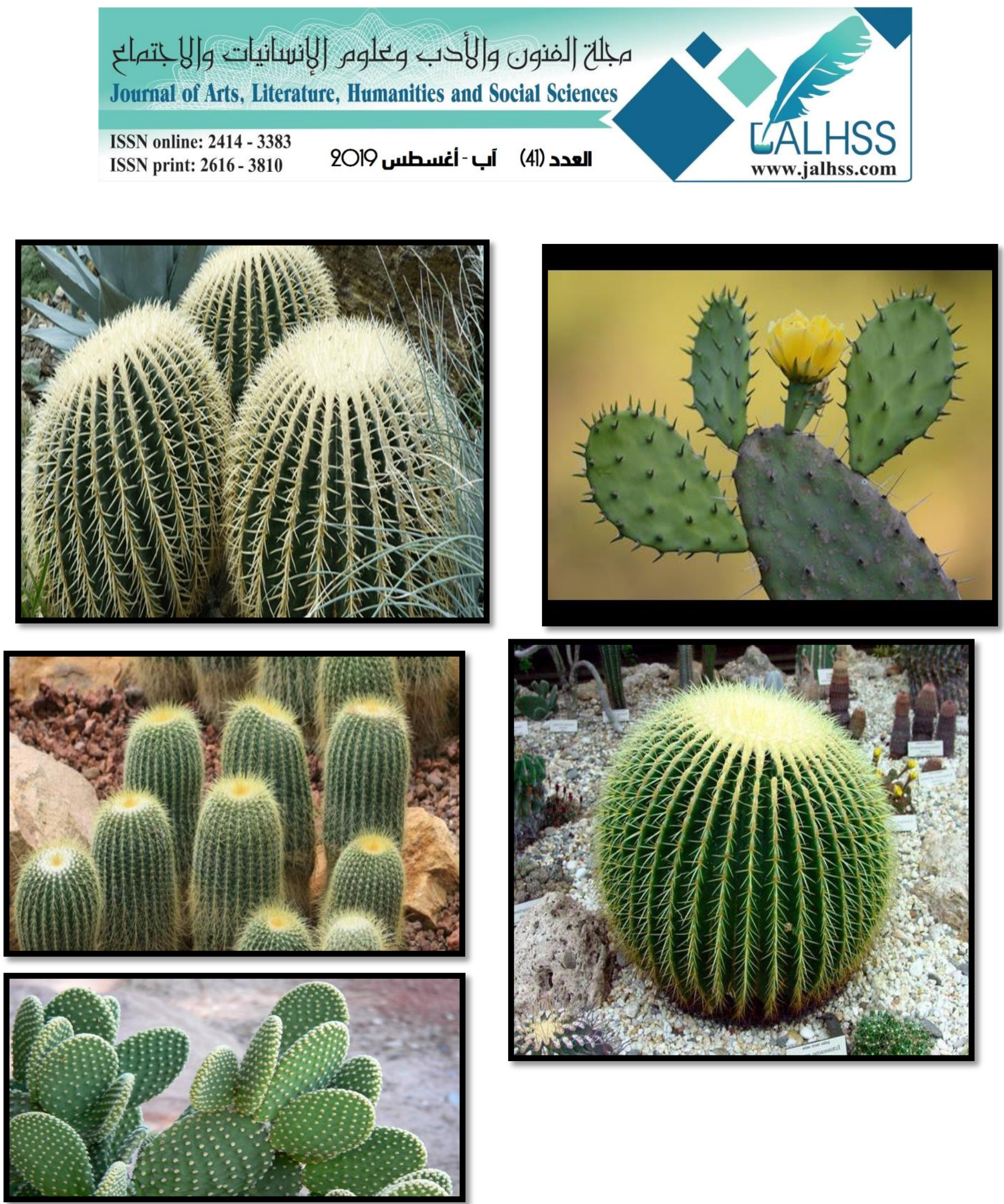

$$
\text { ( مراجع صور الصبار }
$$

https://www.etsy.com/listing/628259134/opuntia-monacantha-drooping-prickly ${ }^{14}$ 


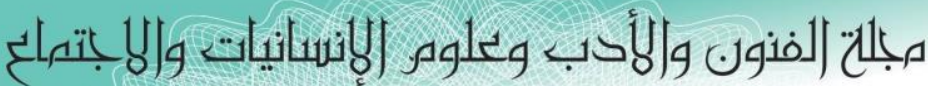

Journal of Arts, Literature, Humanities and Social Sciences

ISSN online: 2414 - 3383

ISSN print: 2616 - 3810

العدد (41) آب - أغسطس 2019

تثانيا: القيم التشكيلية الخطيه لنباتات الصبار:

عناصر التصميم: تانياة

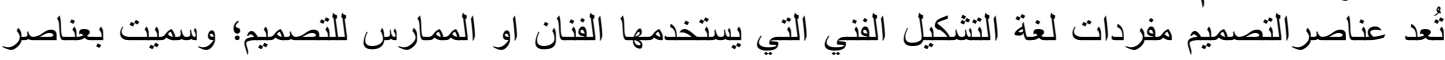

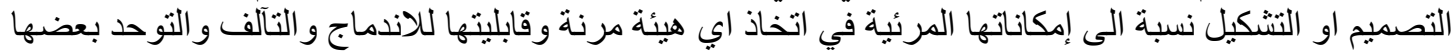

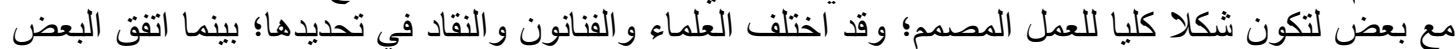

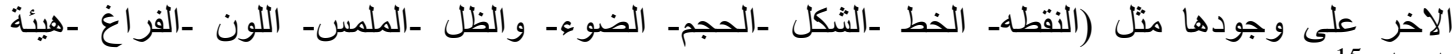
الشكل) 15.

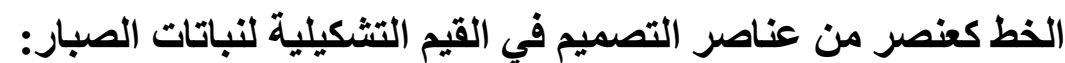

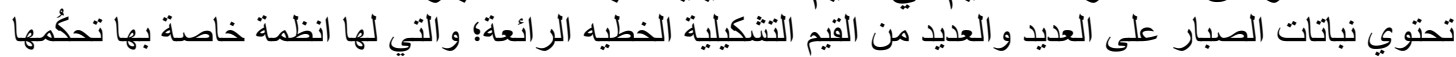

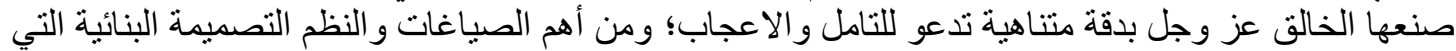

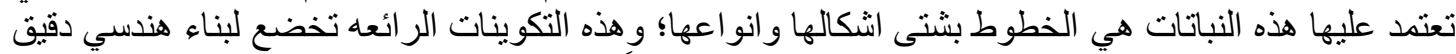

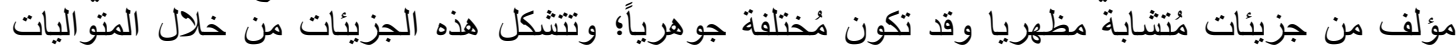

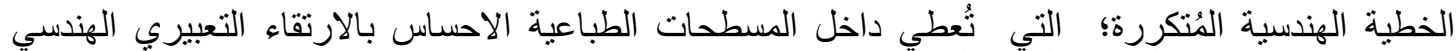

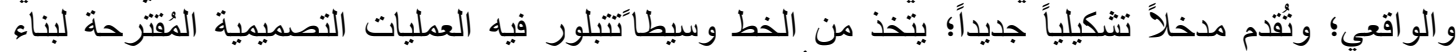

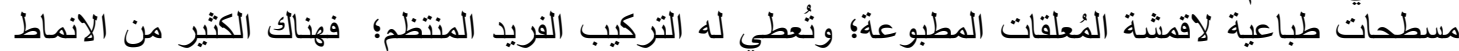

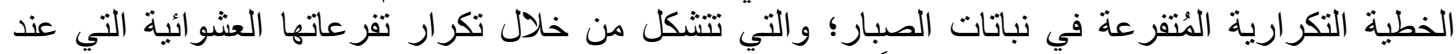

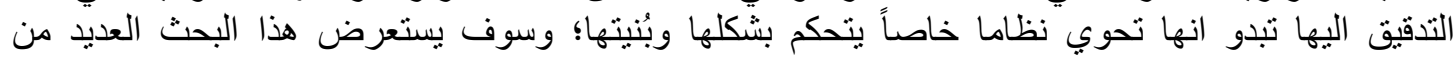

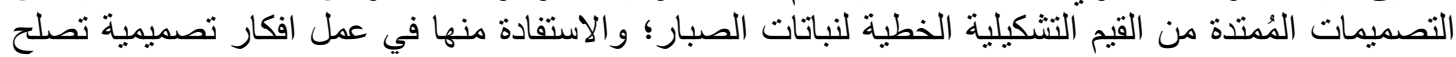

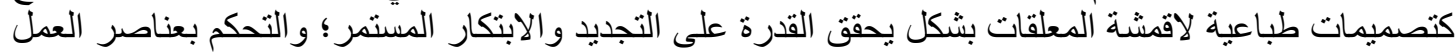

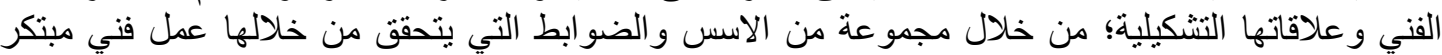
و اصيل؛ بيتمتع بالعديد من القيم الفنية والتشكيلية الخطية شكل (3-4) الإل

وفيما يلي استعر اض لانواع الخطوط حيث تنقسم الخطوط إلى نوعين هما:

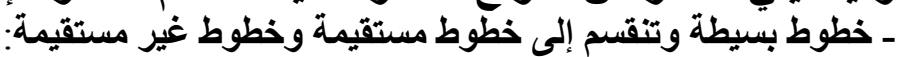

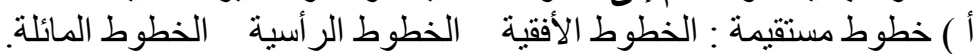

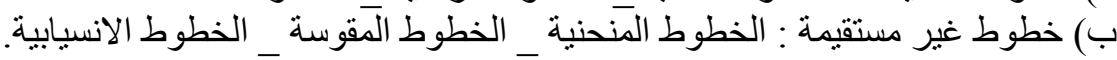

ـ خطوط مركبة وتنقسم إلى خطوط أساسها الخط المستقيم _ خطوط أساسها الخط غير المستقيم _ خطوط أساسها الخط المستقيم وغير النيم المستقيم أو تجمع بينهما:

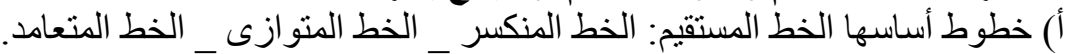

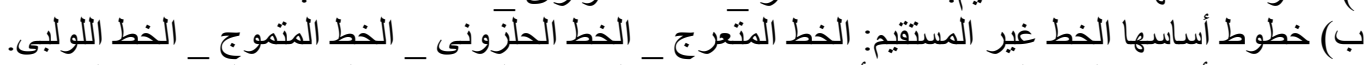

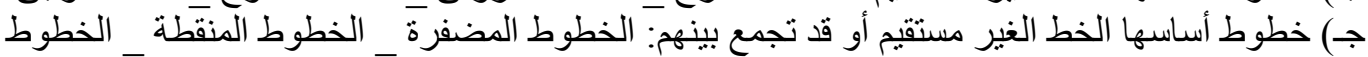

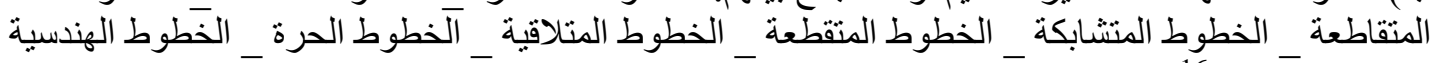
الخطوط المتماسة:16.

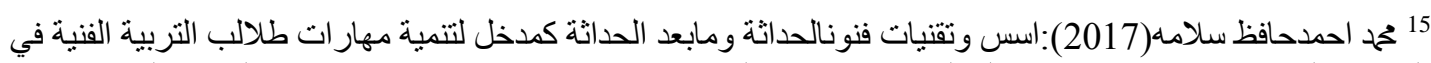

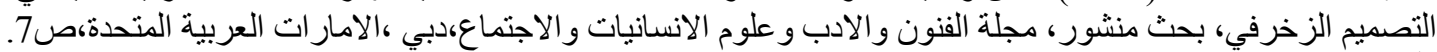
https://artisticdesignacadmy.wordpress.com/page1-2/page-lesson2/ ${ }^{16}$ 


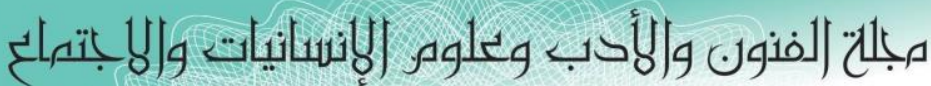

Journal of Arts, Literature, Humanities and Social Sciences

ISSN online: 2414 - 3383

ISSN print: 2616 - 3810

العدد (41) آب - أغسطس 2019

LALLHSS

www.jalhss.com

العلاقات الإنثائية داخل المُسطحات الفنية التي أُستخدمت في عمل تصاميم المُعلقات

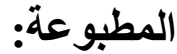

-

ـ و هي من اهم العلاقات الإنشائية في التصميم و التي استخدمت في هذا البحث ؛ و التجريب وسيلة الأداء

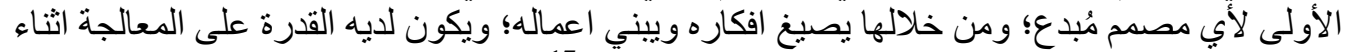

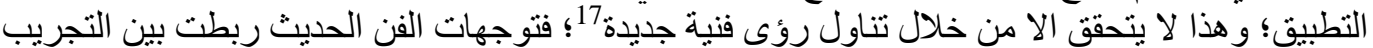

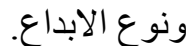

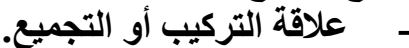

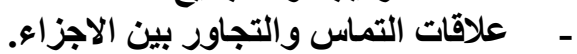

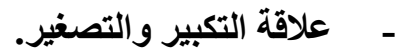

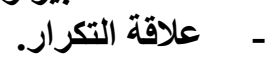

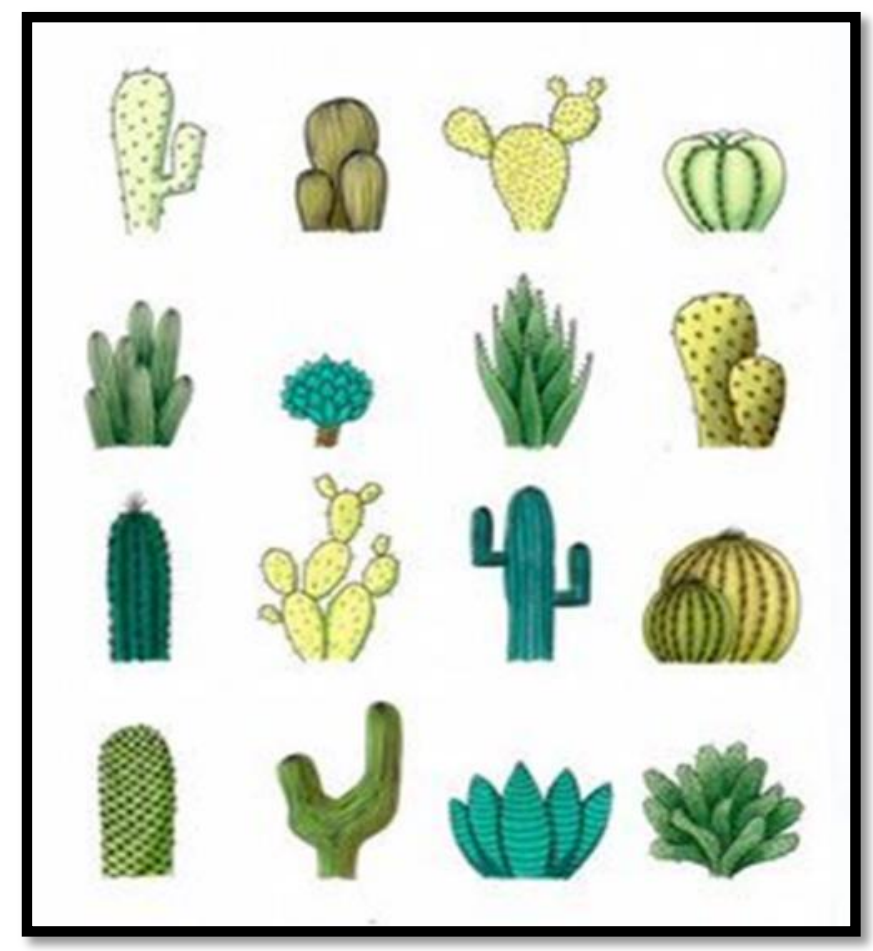

شكل (3) انماط خطية تكرارية مُتفرعة في نباتات الصبار 
مجلحت الفنون والأدب وعلوه الإنسانيات والهبتهماع Journal of Arts, Literature, Humanities and Social Sciences

ISSN online: 2414 - 3383

ISSN print: 2616 - 3810

العدد (41) آب - أغسطس 2019
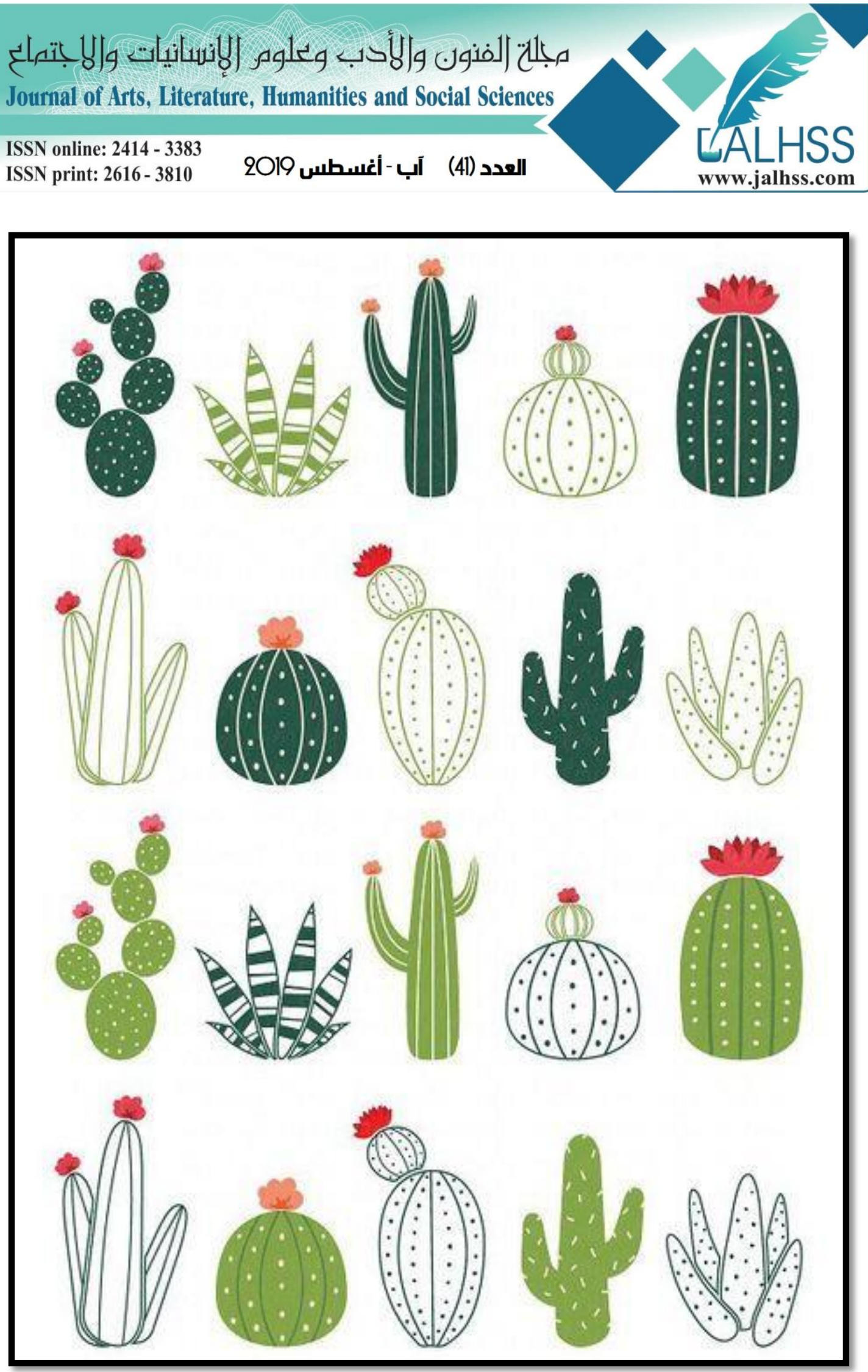

شكل (4) انماط خطية تكرارية مُتقفرعة في نباتات الصبار 


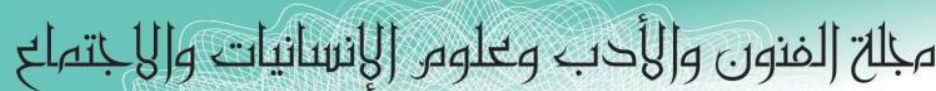
Journal of Arts, Literature, Humanities and Social Sciences

ISSN online: 2414 - 3383

ISSN print: 2616 - 3810

\section{العدد (41) آب - أغسطس 2019}

LALHSS

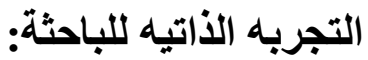

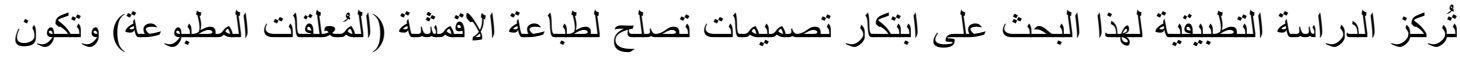

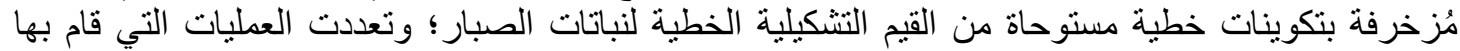

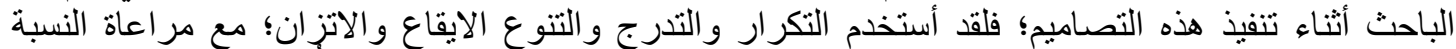

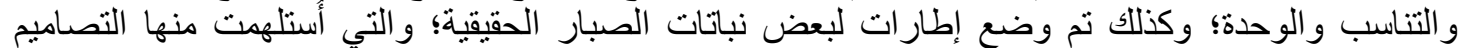

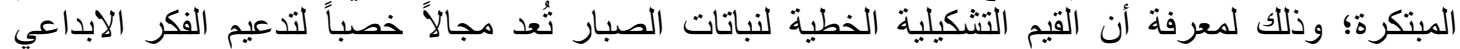

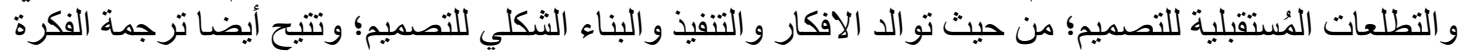

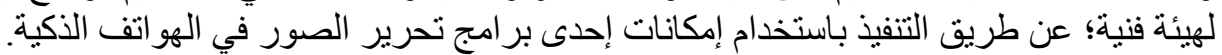

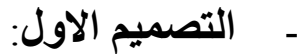

عبارة عن تصميم مستطيل لمجموعة من نباتات الصبار المثمرة وثمار ها لذيذة الطعم وتتمو في منطقة جنوب الطيا

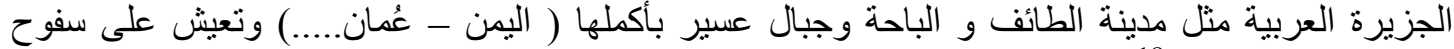

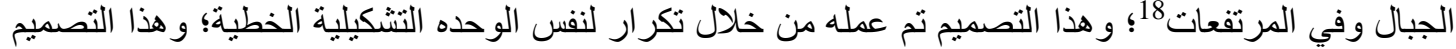

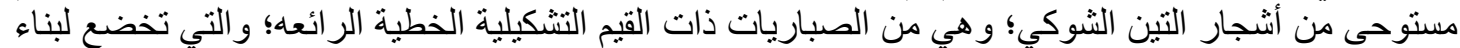

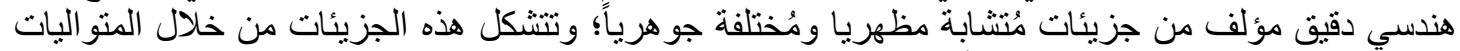

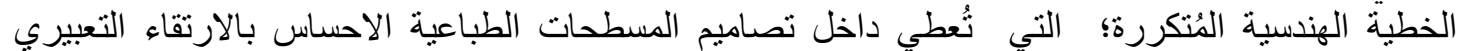
الهندسي و الو اقعي.
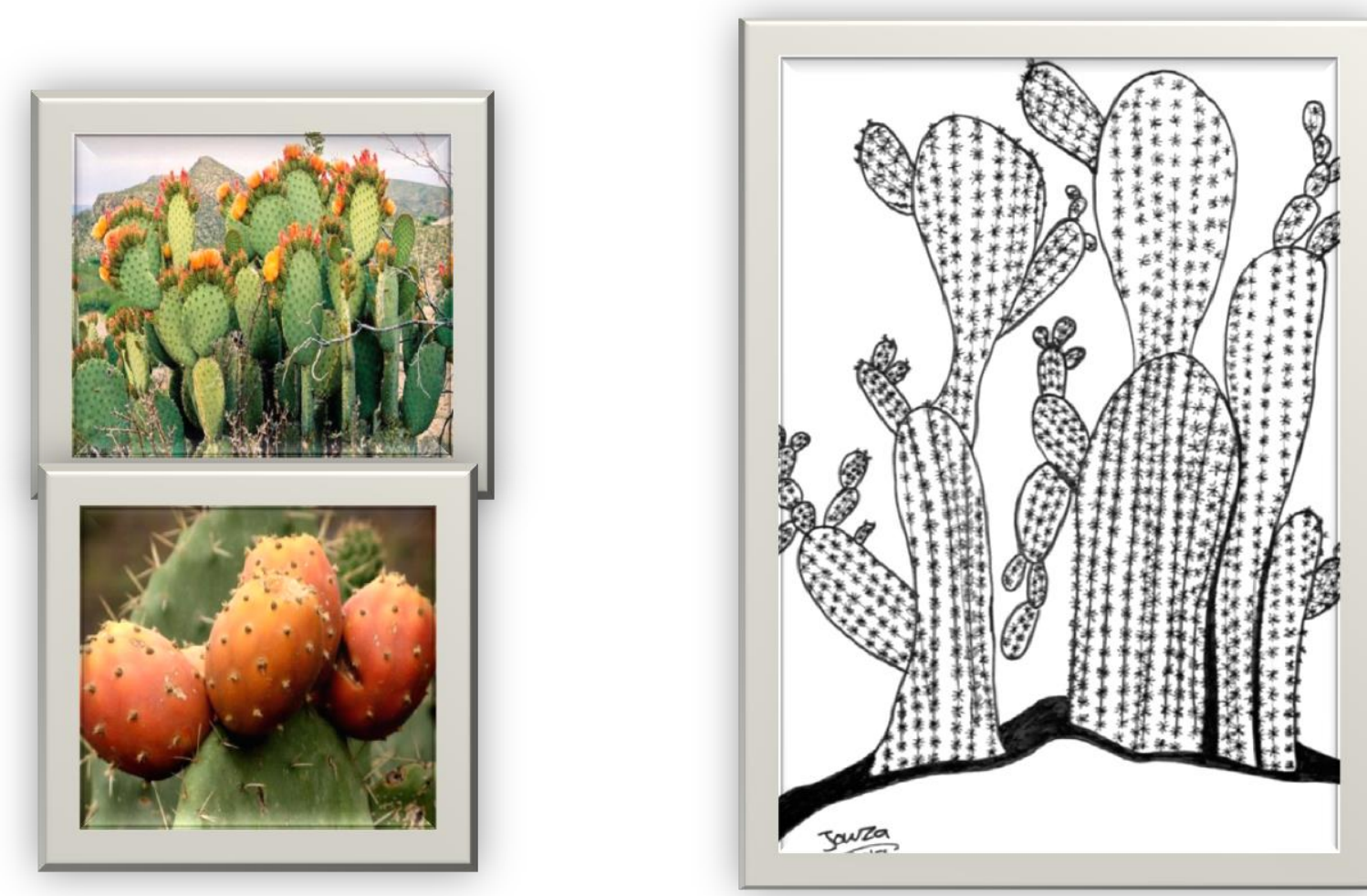

http://www.naseemnajd.com/w/?p=89 ${ }^{18}$ 


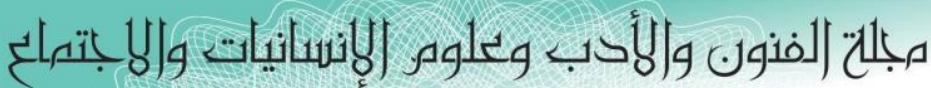
Journal of Arts, Literature, Humanities and Social Sciences

ISSN online: 2414 - 3383

ISSN print: 2616 - 3810

\section{العدد (41) آب - أغسطس 2019}

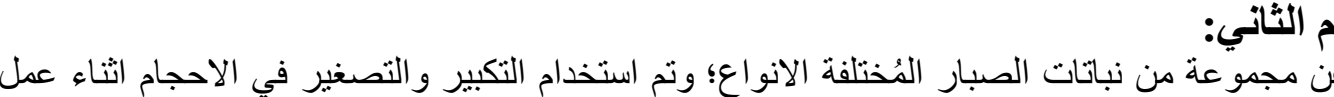

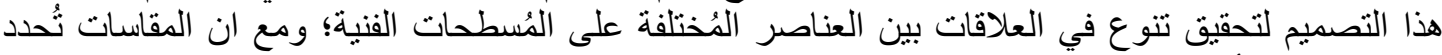

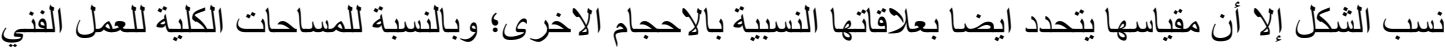

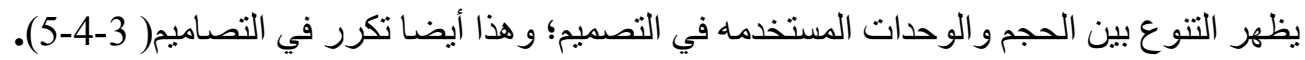

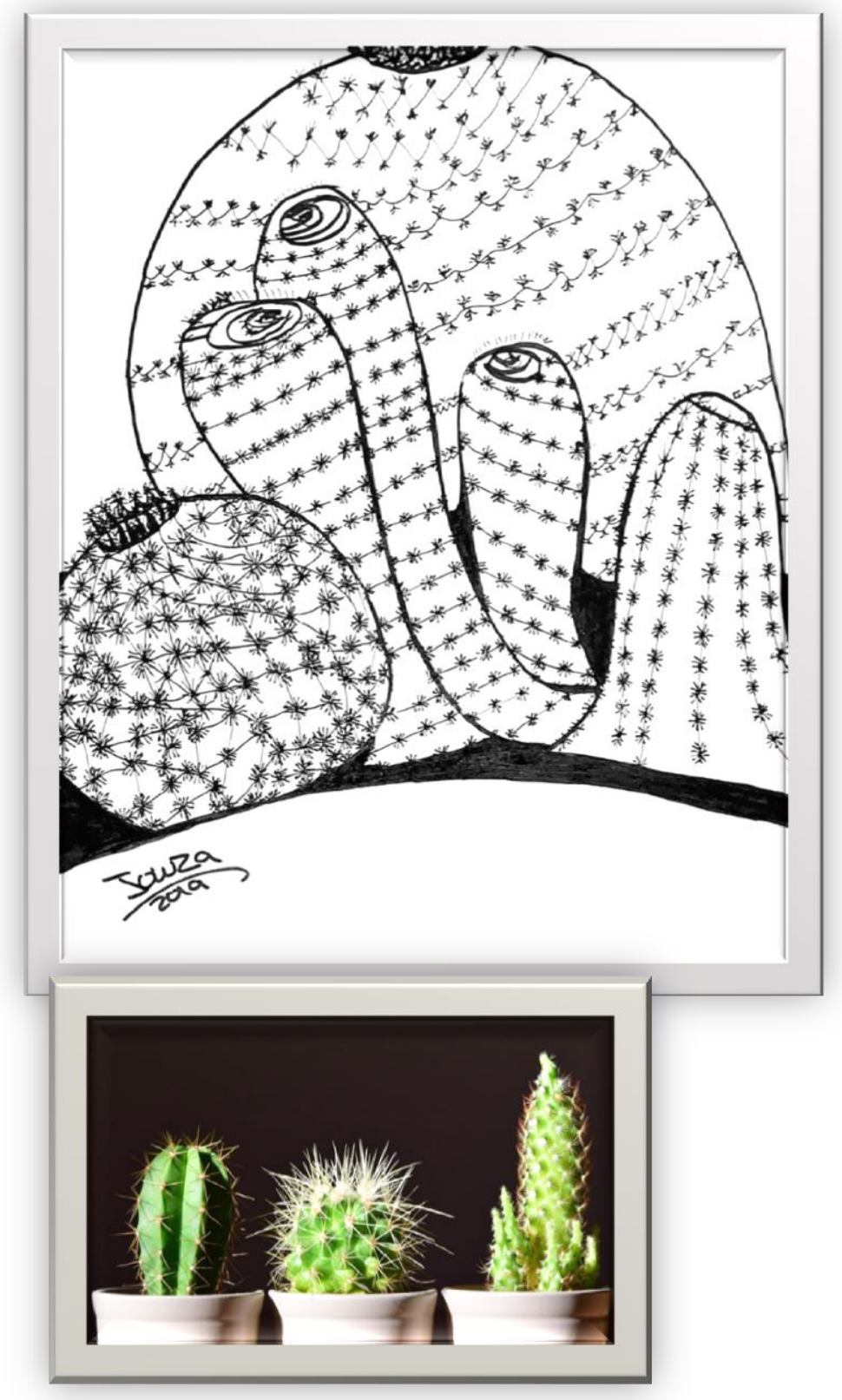



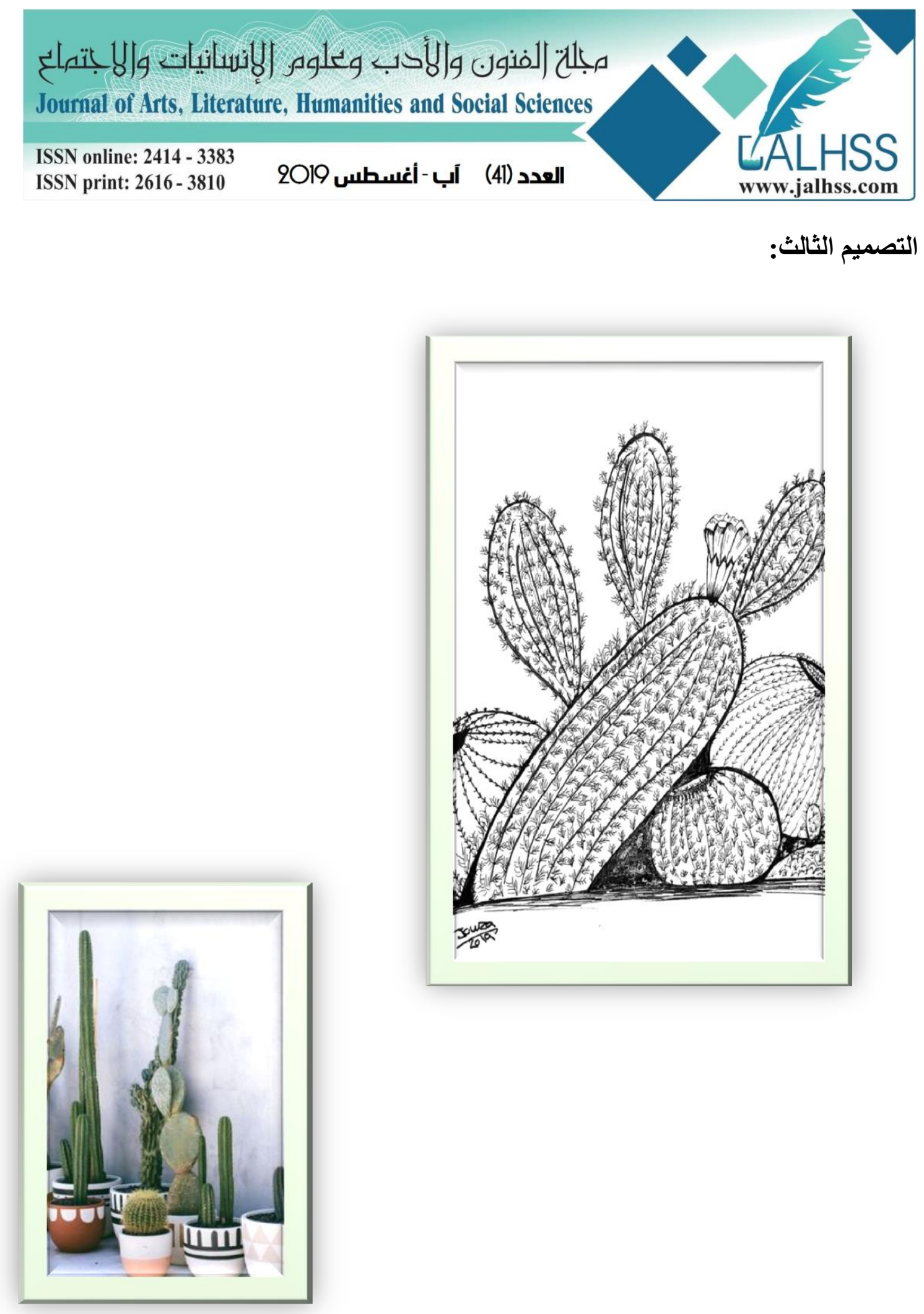


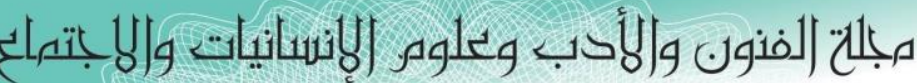

Journal of Arts, Literature, Humanities and Social Sciences

ISSN online: 2414 - 3383

ISSN print: 2616 - 3810

$$
\text { العدد (41) آب - أغسطس } 2019
$$
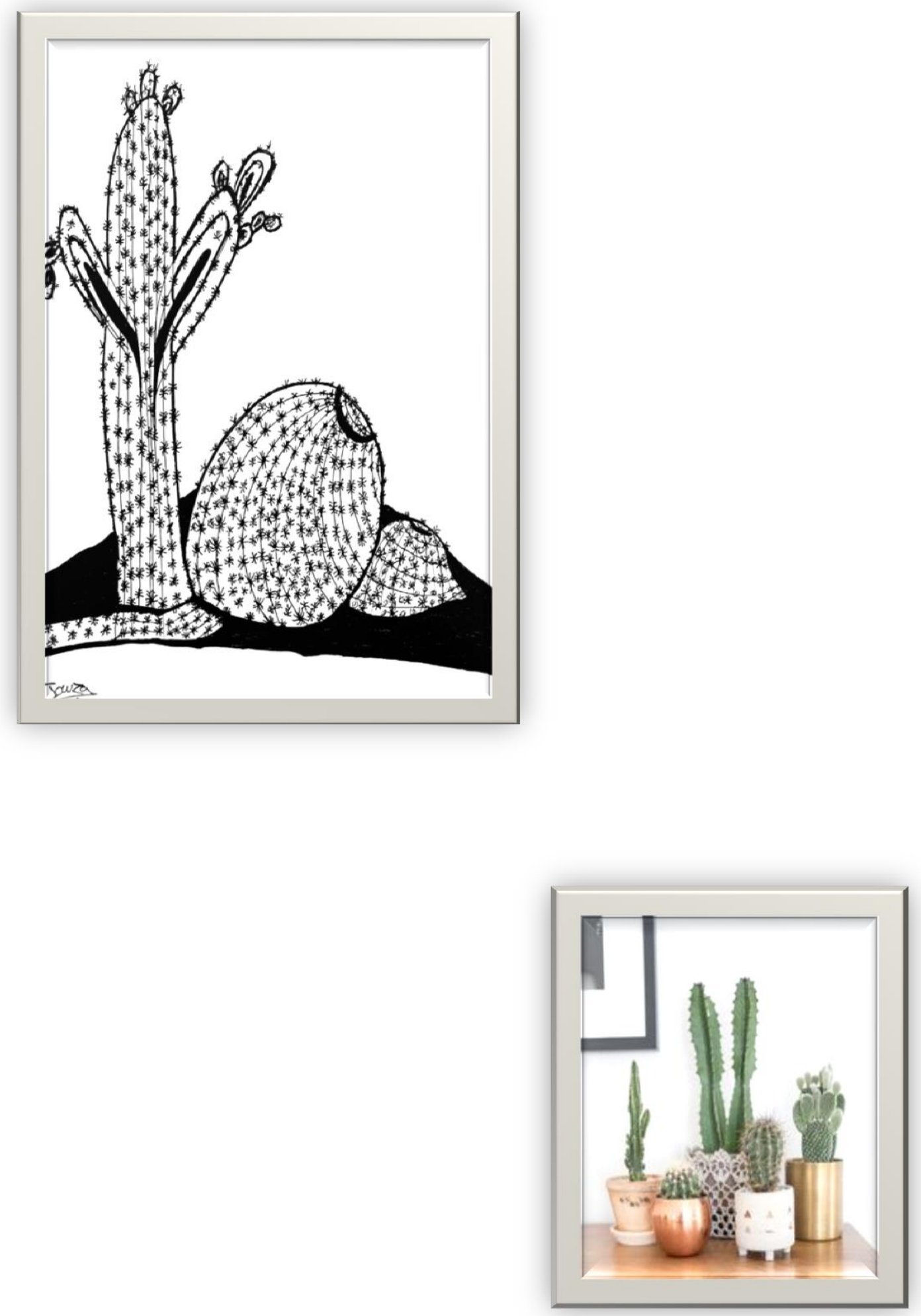


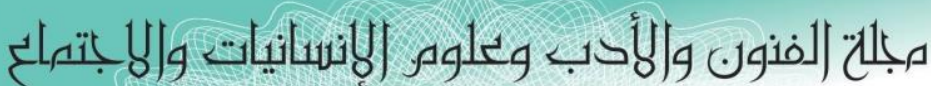

Journal of Arts, Literature, Humanities and Social Sciences

ISSN online: 2414 - 3383

ISSN print: 2616 - 3810

العدد (41) آب - أغسطس 2019

LALHSS

Www.jalhss.com

التصميم الخامس:
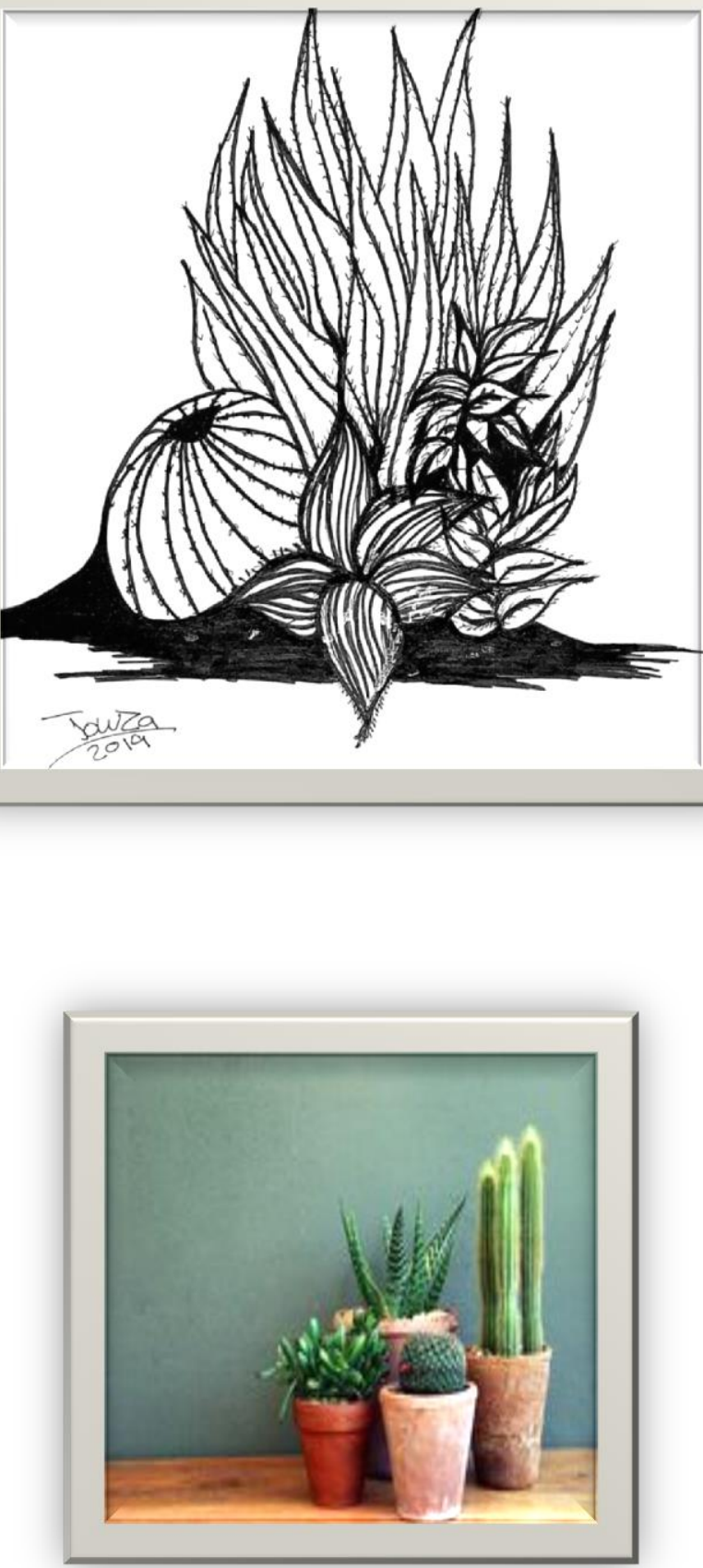


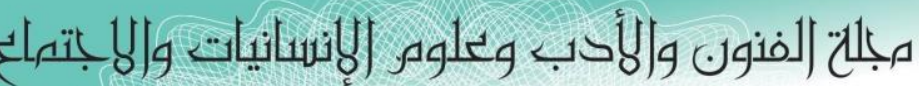

Journal of Arts, Literature, Humanities and Social Sciences

ISSN online: 2414 - 3383

ISSN print: 2616 - 3810

\section{العدد (41) آب - أغسطس 2019}

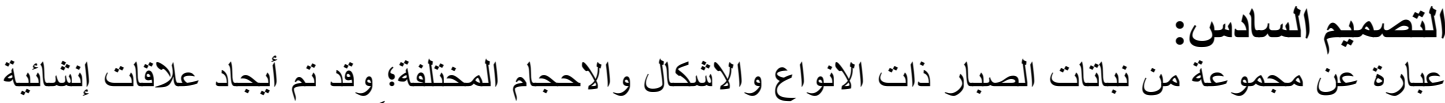

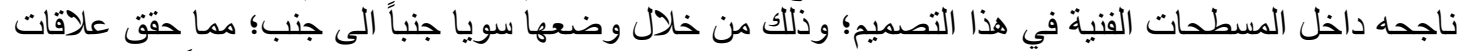

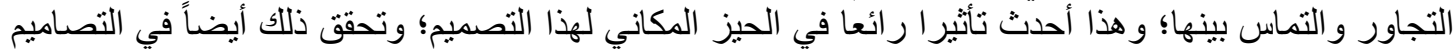

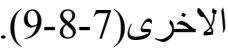
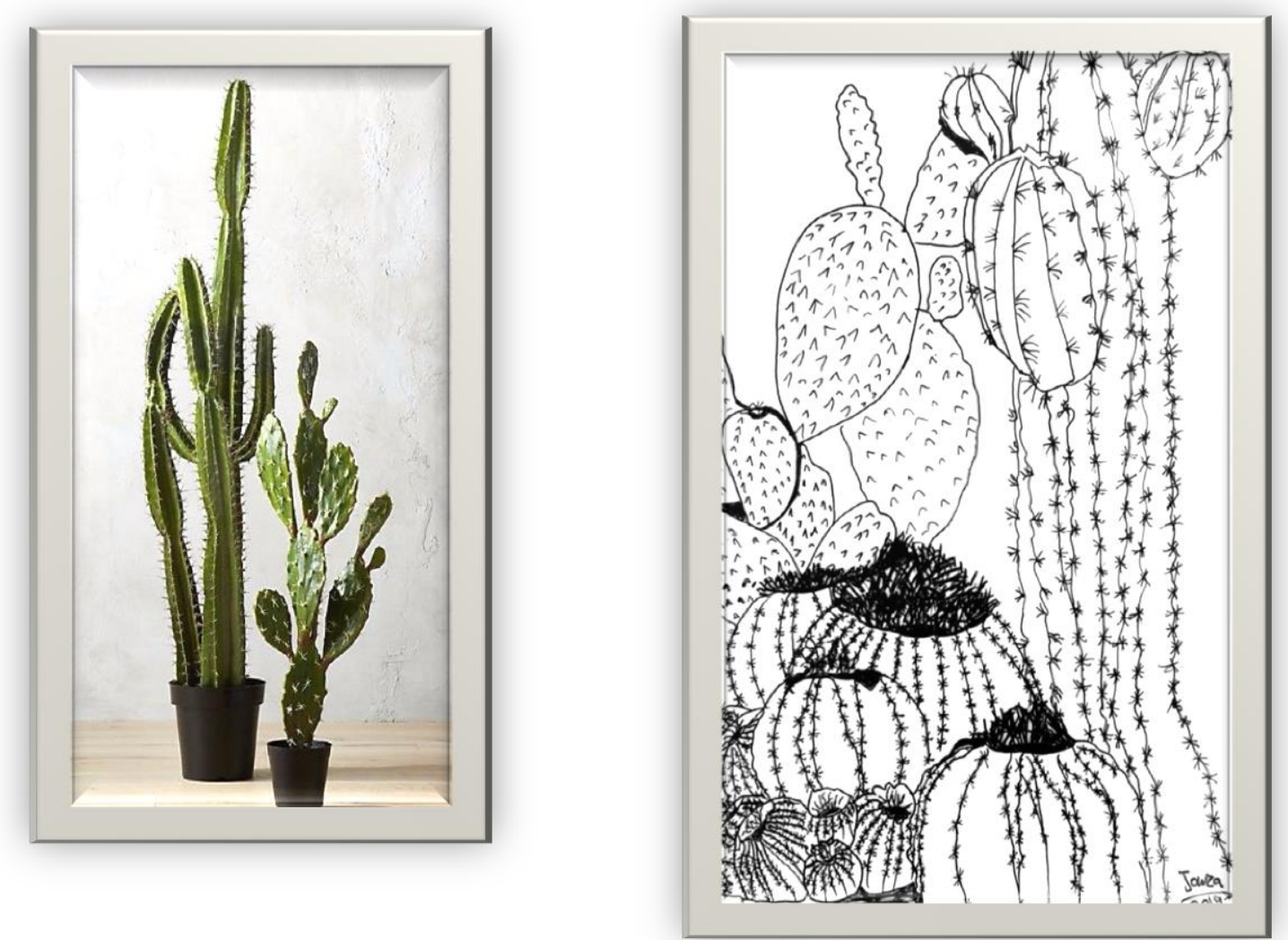


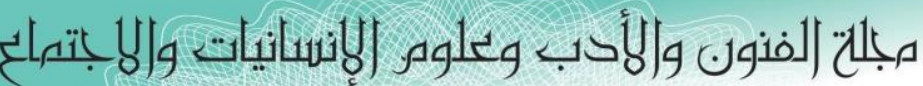
Journal of Arts, Literature, Humanities and Social Sciences

ISSN online: 2414 - 3383

ISSN print: $\mathbf{2 6 1 6 - 3 8 1 0}$

العدد (41) آب - أغسطس 2019

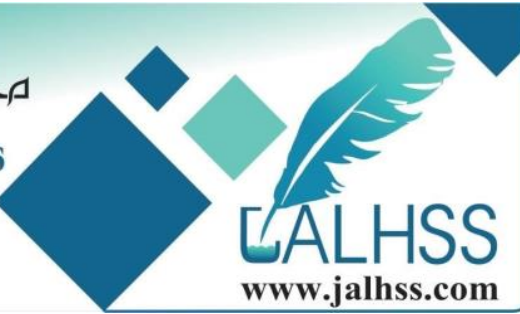

التصميم السابع:
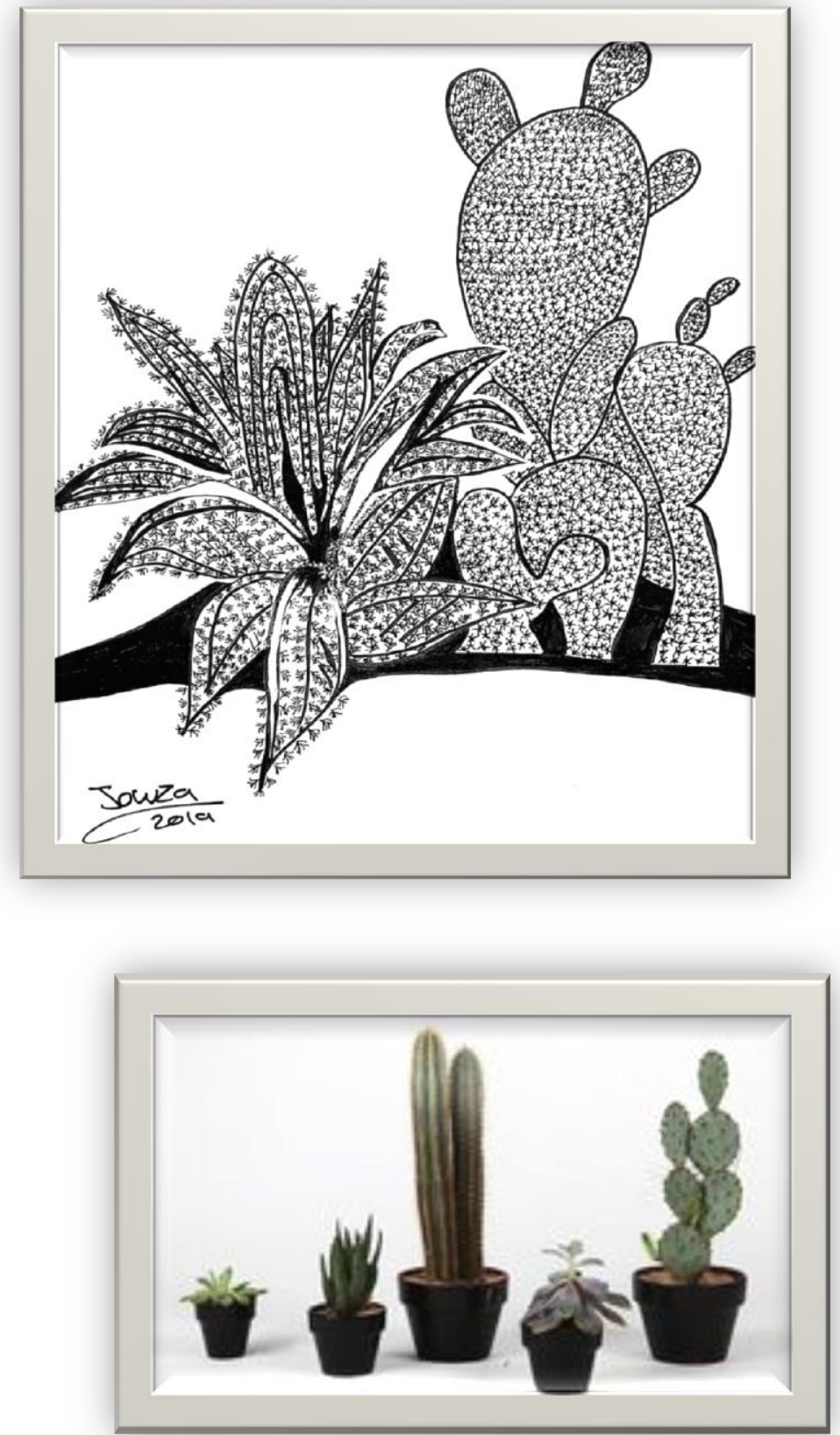


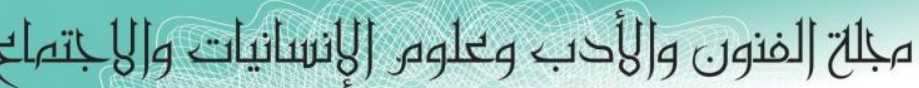
Journal of Arts, Literature, Humanities and Social Sciences

ISSN online: 2414 - 3383

ISSN print: $\mathbf{2 6 1 6 - 3 8 1 0}$

$$
\text { العدد (41) آب - أغسطس } 2019
$$

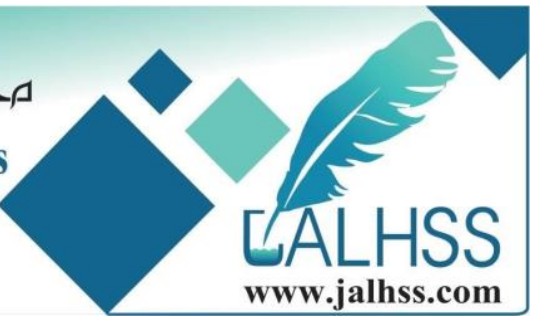

التصميم الثامن:

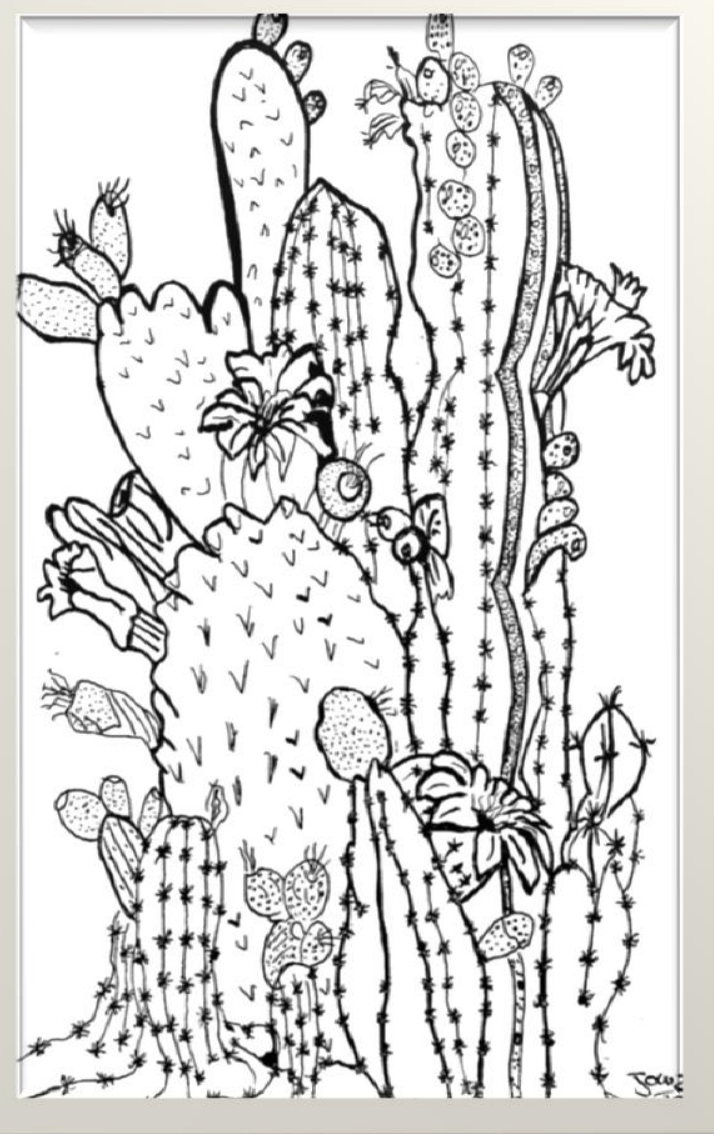




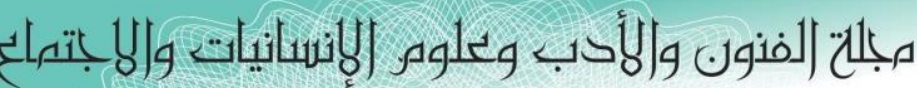

Journal of Arts, Literature, Humanities and Social Sciences

ISSN online: 2414 - 3383

ISSN print: 2616 - 3810

العدد (41) آب - أغسطس 2019
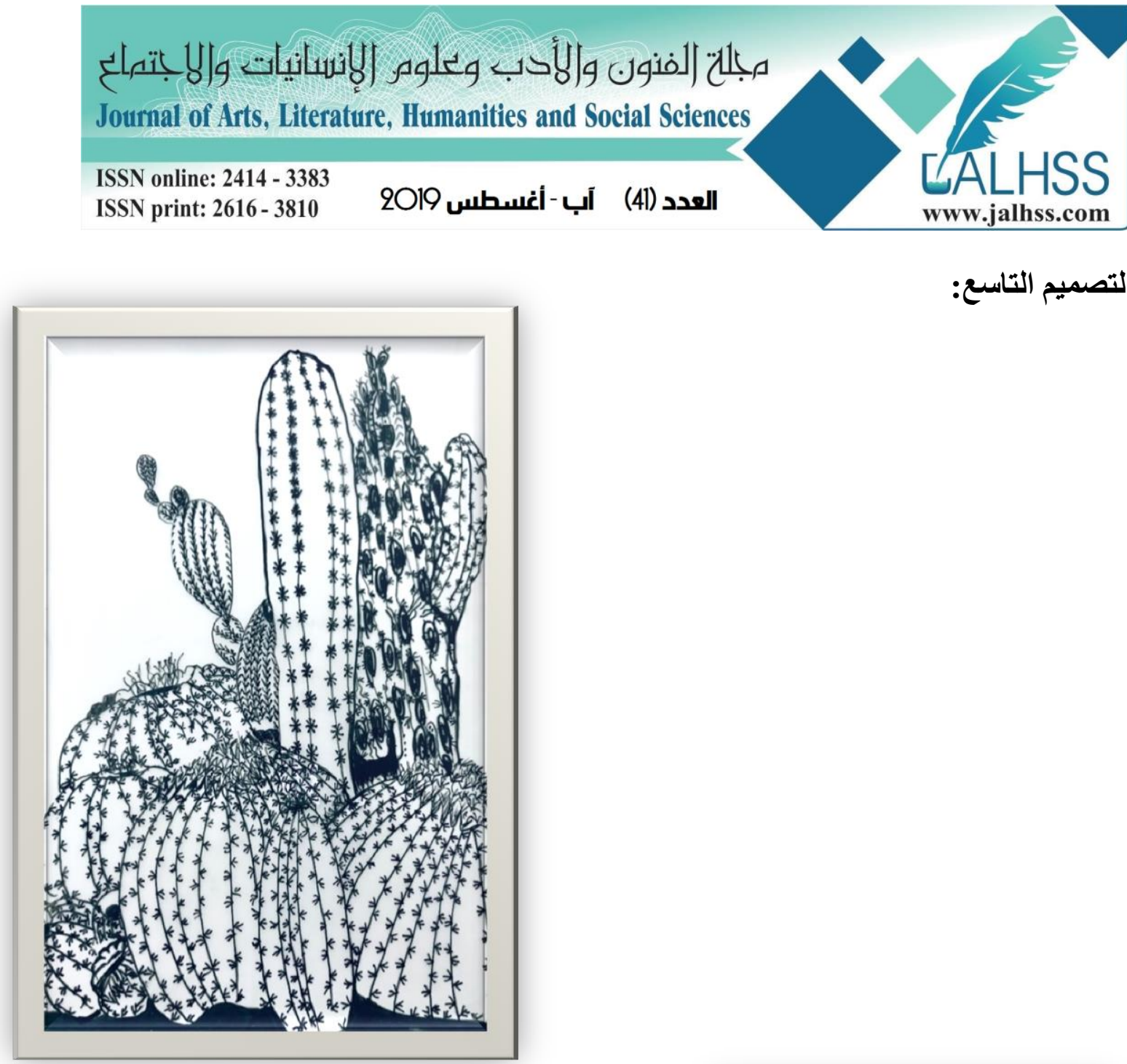

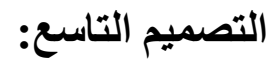

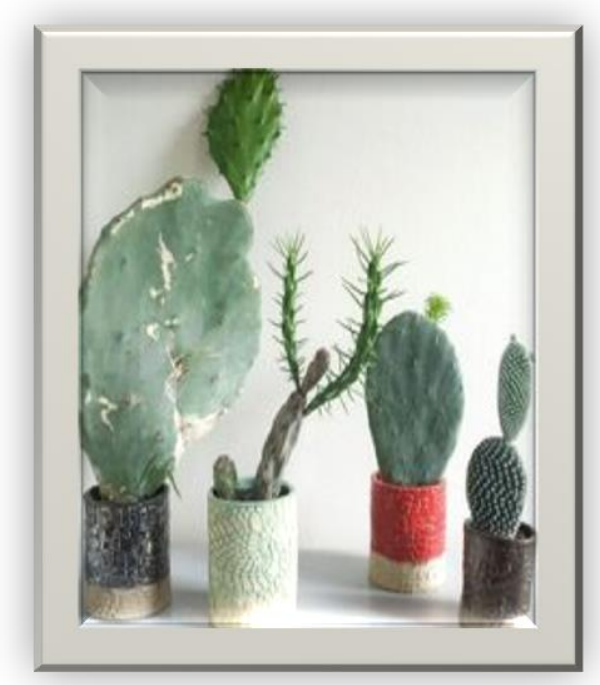




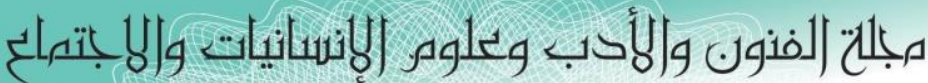

Journal of Arts, Literature, Humanities and Social Sciences

ISSN online: 2414 - 3383

ISSN print: 2616 - 3810

العدد (41) آب - أغسطس 2019

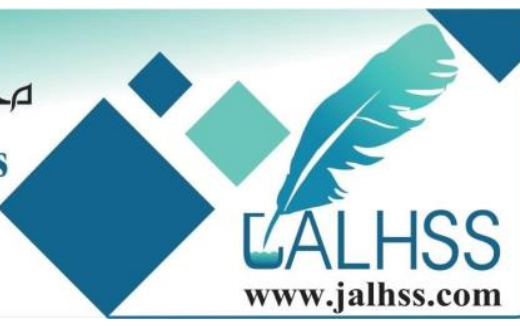

التثائج والتوصياث:

النتائج:

- ساعدت دراسة القيم التشكيلية الخطية لنباتات الصبار على انتاج مجموعة من تصاميم أقششة المعلقات المطبو عة تحمل في ثنايها قيم و ابعاد تشكلية جديدة. - تم التعرف على القيم التشكيلية الخطية لنباتات الصبار كمصدر من مصادية لتكادر الالهام والرؤية الفنية المعاصرة.

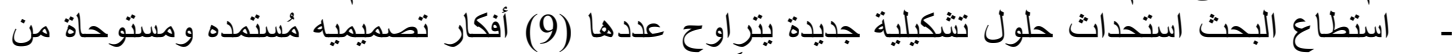

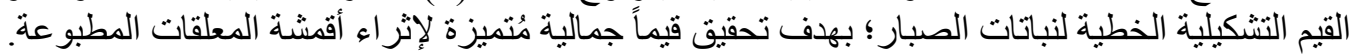

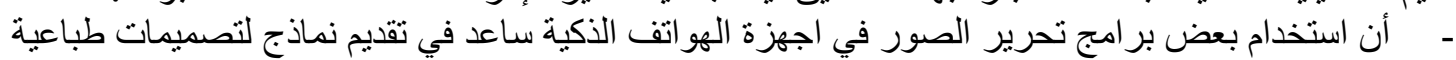

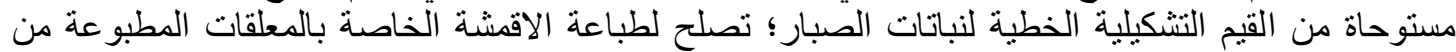
خلال رؤية تصميمية معاصرة.

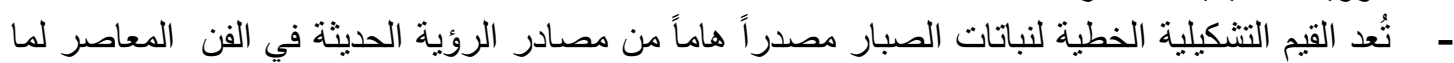
تحتويه من مقومات تشكيلية خطية وجمالية وتنو علية في بنائها الطبيعي.

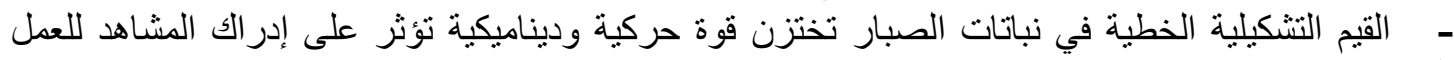
- الفني. إن دراسة النظم الإيقاعية الخطية في نبات الصبار ، تساعد على إيجاد صيغ تشكيلية جديدة للتصميم.

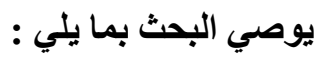

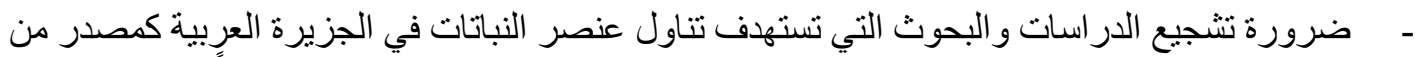

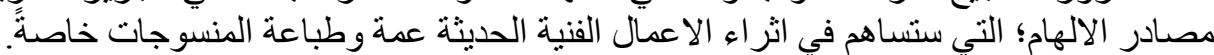

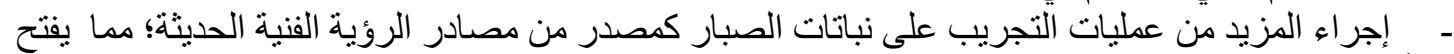
آفاقاً جديدة أمام مصمدي الاقمشئة.

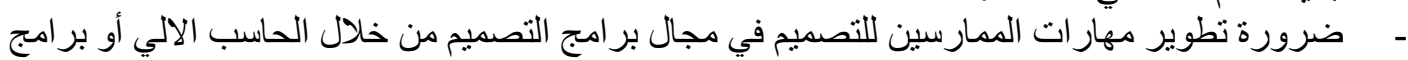
تحرير الصور ومعالجتها بالهو اتف الذكية لدقتهاروسهولة استخدامها. 
مبلحت (لفنون والأدب وتلوه الإنسانيات والبانتهاع

Journal of Arts, Literature, Humanities and Social Sciences

ISSN online: 2414 - 3383

ISSN print: 2616 - 3810

\section{العدد (41) آب - أغسطس 2019}

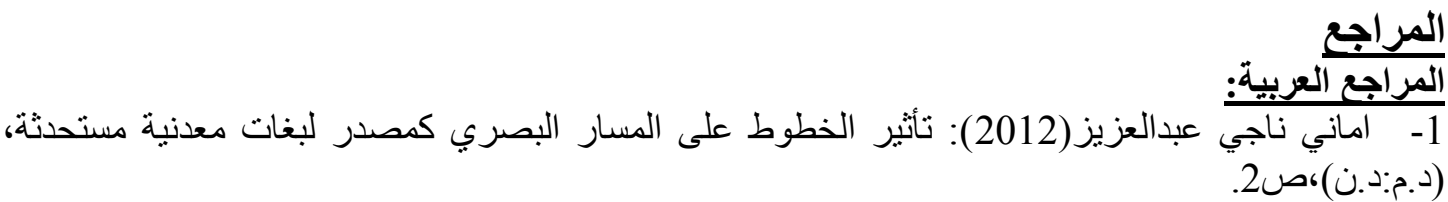

2- احمد العطيات(1993): موسوعة النباتات الطبية اثنارها العلاجيه او الفسيولوجيه، اجزاؤها النباتية

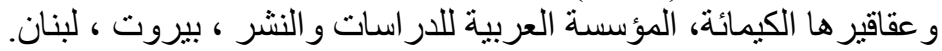

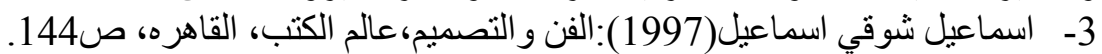

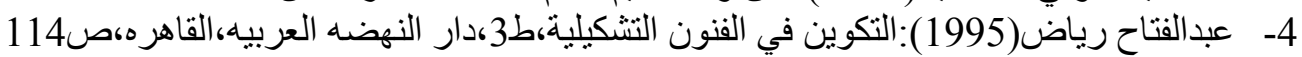

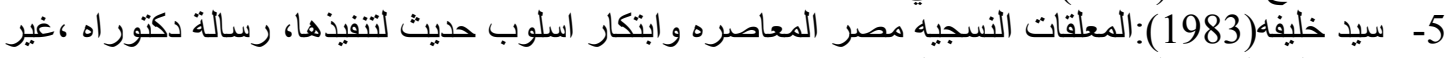

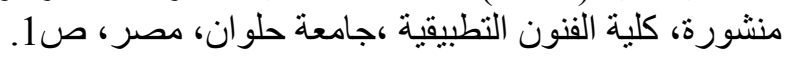

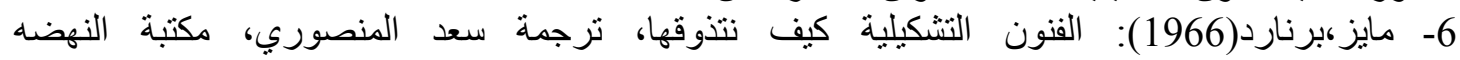

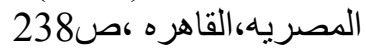
7- مها قاسم السيوف(2011): نبات الصبار ،المركز الوطني للبحث و الارشاد الزر اعي، عمان ، الاردن،ص-8

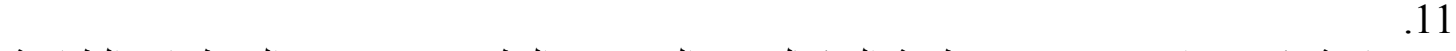
8- مايسة فكري واخرون(2017):نظرية الفركتال بين التجريب و التطبيق في تصميم المسطحات الطباعية لاقمشة المعلقات، بحث منشور، مجلة العمارة والفنون، الجمعية العربية للحضارة والفنون الفنون الاسلامية، القاهرة،

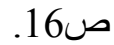

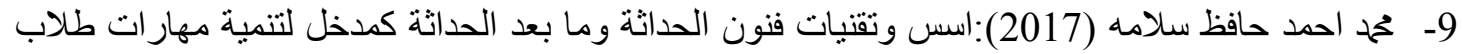

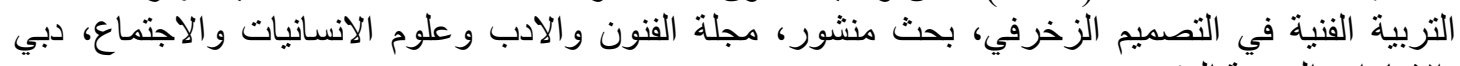

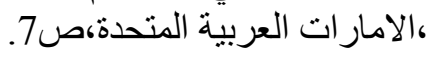

المراجع الأجنبية

10-Agarry, O, O, Opaleye, M, T (2005): Comparative Antimicrobial, Activities of Aloe Vera gel and leaf, Biotechnol.4, (12),1413-1414.

11-Reynolds, T,Dweck,A,C(1999): Aloe Vera Leaf gel, a review update,J,Ethnopharmacol,68,3-37.

\section{المواقع الاكترونية}

https://mawdoo3.com/\%D8\%B9\%D9\%86\%D8\%A7\%D8\%B5\%D8\%B1_\%D8\%A7\% D9\%84\%D9\%81\%D9\%86

http://www.naseemnajd.com/w/?p=89

https://www.khayma.com.hawij

https://artisticdesignacadmy.wordpress.com/page1-2/page-lesson2/

https://www.etsy.com/listing/628259134/opuntia-monacantha-drooping-prickly 